\title{
Sexualidades costeñas
}

\author{
Patricia Ponce
}

\section{HERENCIASY NUEVAS MIRADAS}

$\mathrm{L}$ AS SOCIEDADES occidentales somos herederas —en parte— de la tradición judeocristiana cuyas valoraciones y conceptualizaciones sobre la sexualidad tienen sus orígenes en los preceptos del judaísmo y el estoicismo helénico y romano que organizan un nuevo sistema sexual basado en el matrimonio religioso, como único espacio legítimo para ejercer la sexualidad orientada exclusivamente a la reproducción; la desaprobación de la homosexualidad y del sexo realizado solamente por placer. Al paso del tiempo esta moral cristiana se ha generalizado formando parte del sentido común, nuestro comportamiento sexual va siendo moldeado por esta cultura que acompaña al surgimiento y desarrollo del Estado moderno. Siguiendo a Foucault, las prácticas sexuales hasta finales del siglo XVIII estaban regidas por la ley civil, la pastoral cristiana y el derecho canónico; a partir de ese siglo, y a lo largo del XIX empiezan a surgir las instituciones, saberes y normas que aunque cada vez más laicas se convierten en las herederas de la moral cristiana. La valoración sobre la sexualidad pasó de manos de la Iglesia a los representantes de la higiene

PATRICIA PONCE: Doctora en ciencias sociales, área de familia y género, Universidade Estadual de Campinas, São Paulo, Brasil. Investigadora titular del CIESAS-Golfo.

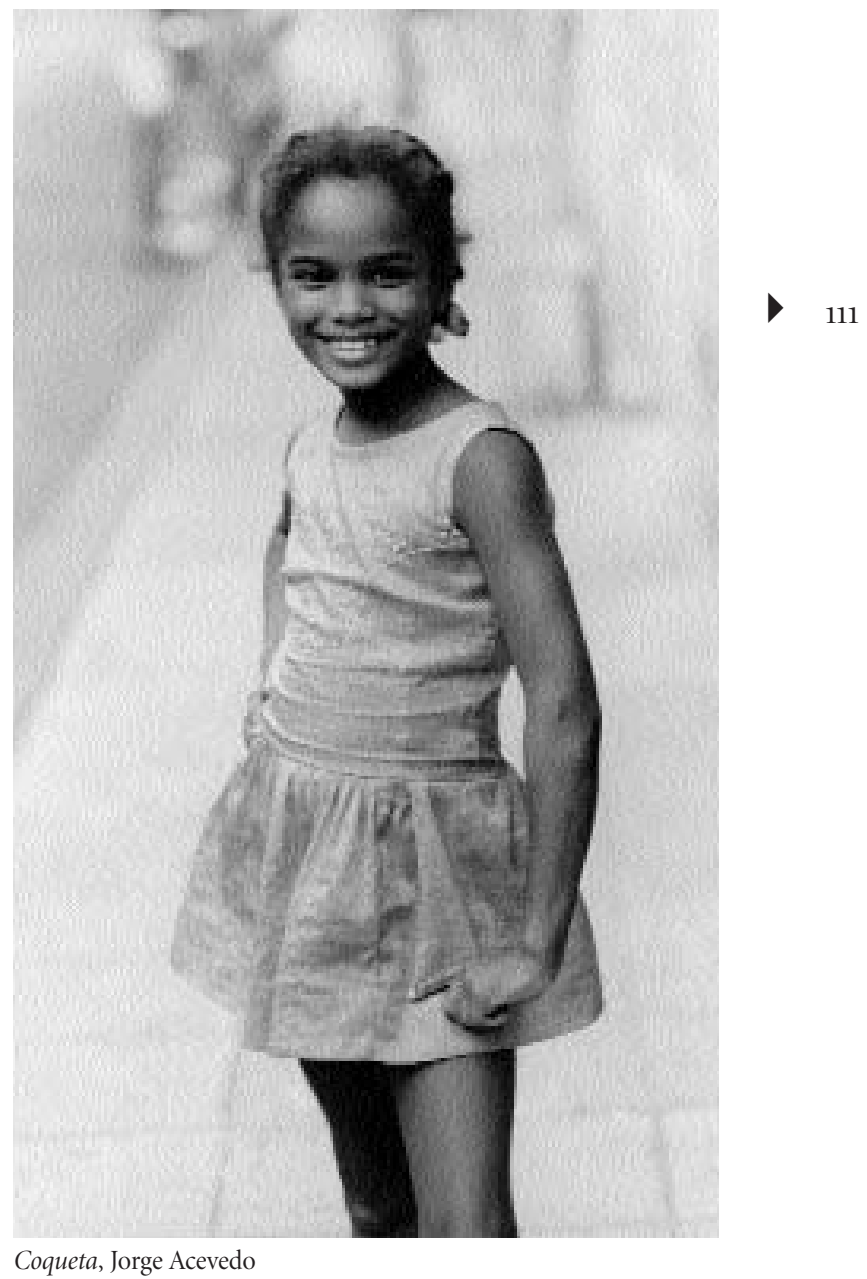




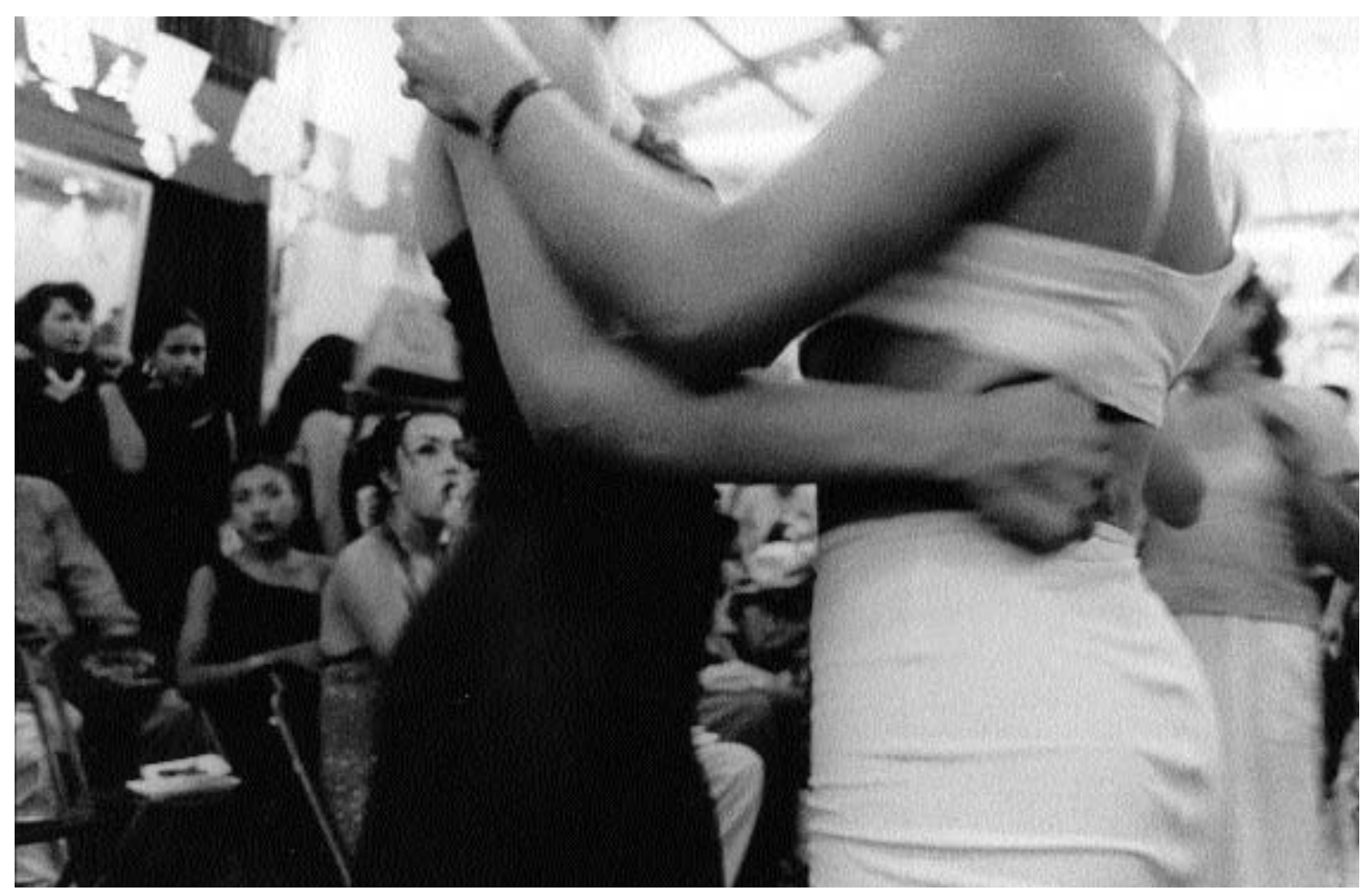

Cinturas, Jorge Acevedo

social y mental sin que hubiera un claro rompimiento entre ciencia y religión.

Con el desarrollo del capitalismo la problemática poblacional y la demografía se convierten en un asunto de Estado en donde el sexo es incorporado a las políticas públicas buscando su regulación a través de diferentes instancias y discursos "científicos" acordes a la nueva racionalidad productiva y familiar. Las familias (en especial los padres), apoyadas por sacerdotes, pedagogos, psiquiatras, sexólogos y médicos, se dieron a la tarea de establecer las normas morales y sociales, convirtiéndose en los principales agentes reproductores de la sexualidad normativizada. Los pecados de San Pablo se transforman en "enfermedades" y la clínica, "en el confesionario moderno". Surgen los análisis y los diagnósticos de las prácticas sexuales en donde el deseo es visto como peligroso y el cuerpo como un elemento ajeno, sucio, que es necesario aprender a controlar. El discurso médico crea un enorme catálogo de "patologías", "perversiones", "desviaciones", "anormalidades", las cuales debían ser condenadas y castigadas. Se organizan controles pedagógicos, médicos, religiosos, en donde la pareja monogámicareproductiva se convierte en el único modelo universal válido al ser considerada "médicamente saludable" (Foucault, 1993). Así, los discursos médico y psiquiátrico logran construir un campo de poder sobre la sexualidad: el poder de representar, el de las representaciones y la construcción de nuevos sujetos sociales, nuevas subjetividades que originan nuevas identidades (Núñez, 1994).

En nuestras culturas, la moralidad de nuestros comportamientos sexuales ha dominado las teorías sobre la sexualidad, bajo el disfraz de la "cientificidad" han pretendido justificar las diferencias, las preferencias, la desigualdad, creándose una serie de principios conceptuales y valorativos que aún dominan el ejercicio de nuestra sexualidad, y en donde éste se ha convertido en un espacio de vital importancia para definir el destino y la pertenencia (Weeks, 1998). 
Hasta hace algunos años eran pocas las personas autorizadas para hablar y escribir sobre sexualidad, casi todas ellas pertenecían al ámbito religioso, médico, pedagógico o psicológico y, para ser aceptados sus discursos como "verdaderos" o "científicos", debían contar con títulos de prestigiadas universidades. Aún son escasas las revistas o libros académicos que nos hablan sobre la construcción de las sexualidades; no obstante, en la vida cotidiana la sexualidad se practica, se vive, se disfruta y forma parte del lenguaje del día a día a través de señas, gestos, chistes, albures, décimas, bailes, canciones, del cine o el teatro. En las últimas tres décadas ha habido un cambio paulatino al respecto. Los estudios sobre las sexualidades han aumentado considerablemente, y la temática ha ganando espacios académicos y científicos bastante respetables, aunque como sostiene Vance (1989: 19), "el sexo siempre es culpable mientras no se demuestre lo contrario". Esta nueva historia - como plantea Jeffrey Weeks — ha reconocido que la sexualidad ha jugado un papel determinante en el desarrollo del pensamiento político, científico, social, moral, y que para su estudio es necesaria una mirada multidisciplinaria. Sin duda alguna, uno de los logros más importantes de este enfoque histórico es la posibilidad que nos da para cuestionar y analizar críticamente este campo de estudio e investigación.

Para la corriente construccionista (Weeks, 1986; Caplan, 1987; Vance, 1991) la sexualidad no es un hecho dado, fijo o permanente vinculado directamente con un impulso biológico natural, las diferencias anatómicas o las relaciones coitales, sino una construcción histórica y sociocultural cambiante que varía de acuerdo con la cultura, la época, la región geográfica, el grupo social, las generaciones y etnias, y es producto de una compleja y diversa red de prácticas discursivas y sexuales en donde las premisas, significados y acciones son partícipes en las percepciones que los seres humanos construyen sobre su conducta sexual, al mismo tiempo que orientan y regulan sus sentimientos, deseos y fantasías eróticas. No niegan la importancia de la biología o los procesos mentales en la conformación de la sexualidad pero rechazan la idea de que éstos sean los responsables de las formas y las prácticas sexuales, ven en ellos una serie de potencialidades que se transforman y adquieren sentido y significados en las relaciones sociales.

Aunque se reconoce el papel preponderante que juega la sexualidad en el funcionamiento del poder, es decir, en cómo el Estado, a través de sus reglamentaciones morales (religiosas, legales, médicas), organiza, moldea, orienta, prohibe, castiga, regula o reprime nuestras prácticas, deseos, fobias sobre el placer; al mismo tiempo se resalta que éste es un campo de lucha, en donde los seres humanos participamos activamente subordinándonos y/o generando oposiciones, negociaciones y resistencia. "El poder de las representaciones vive con nosotros, organiza nuestras prácticas más insignificantes, orienta nuestros deseos, habita en nuestra intimidad, construye nuestras fobias y nuestras furias, nuestras manías, nuestras histerias, nuestras posibilidades de gozo, de placer, nuestro sentido de estar bien y hasta nuestras pesadillas" (op. cit., Núñez, 1994: 29). En este sentido, hombres y mujeres nos hacemos partícipes del poder, pero al mismo tiempo resistimos ante él de manera individual y colectiva.

Esta corriente de pensamiento es el resultado de la interacción de múltiples enfoques y tradiciones del pensamiento social y de movimientos sociales-políticos. La teoría de la construcción social se nutrió del desarrollo de varias disciplinas entre las que destacan el psicoanálisis, la sociología, antropología, los pensamientos feministas y la "nueva historia social", y por otro lado, el surgimiento y fortalecimiento de importantes movimientos políticos como el feminista y el lésbico-gay.

Los trabajos de diversos antropólogos y sociólogos, entre los que destacan Malinowski, Mead, Benedict, Strauss, Gagnon, Simon y Plumer, contribuyeron a evidenciar la diversidad cultural y el carácter relativo y construido de la moral sexual de los diferentes grupos humanos investigados, lo que permitió validar la diversidad de los esquemas sexuales de otros pueblos y comprender la propia diversidad del mundo occidental. No obstante, estos cientistas sociales no escaparon al modelo esencialista al subrayar el papel de la modelación social sobre los individuos y al dejar de lado el papel activo de los mismos, al no cuestionar la sexualidad "natural", a pesar de reconocer las diferencias, y sostener la esencia inmutable de la biología y psicología y al reafirmar la necesidad 
de la división social del trabajo de acuerdo con las diferencias anatómicas de los sexos (op. cit., Weeks, 1998; Vance, 1991).

El psicoanálisis freudiano y el análisis de Foucault, desarrollado dos generaciones después, son otras fuentes importantes en la conformación de "la nueva teoría sexual”. El psicoanálisis hace una revisión del concepto de sexualidad, cuestiona la supuesta predestinación biológica y social de hombres y mujeres lo que constituye una fuerte crítica a las teorías esencialistas sobre la masculinidad-feminidad y las diferencias sexuales, al mismo tiempo que reconoce la existencia del inconsciente y la compleja interrelación entre las construcciones mentales, las exigencias culturales y nuestros deseos. Por su parte, Foucault sitúa a la sexualidad como una construcción sociohistórica, compuesta por una compleja red de relaciones y prácticas sociales heterogéneas que producen significados. Aquí la sexualidad ya no es vista solamente como un conjunto de estímulos biológicos preexistentes, sino como un fenómeno mental, subjetivo que se conforma en el curso de las prácticas sociales históricamente determinadas, que otorga significados a la identidad individual, y como elaboración social que funciona dentro del campo de poder, haciendo hincapié en que éste no es una fuerza homogénea represiva que solamente establece límites y genera disciplinas, sino un fenómeno movilizador. Las críticas más fuertes hacia Foucault han venido de ciertas corrientes del feminismo, quienes consideran que puso demasiado énfasis en la sexualidad en detrimento del género lo que le impidió analizar las diferencias sexuales y la regulación diferenciada de la sexualidad (Lamas, 1998).

La incorporación del sistema sexo-género, como categoría de análisis, introducida en la discusión académica del feminismo por Rubín (1986) y Scott (1996) permite concebir a las relaciones genéricas como construcciones sociohistóricas, sujetas a la transformación, poniendo el énfasis en la dimensión relacional y la perspectiva de la subjetividad; rescatando a las mujeres en su diversidad histórica, de clase, étnica y generacional como actores activos de los procesos sociales. Otros dos aportes importantes del sistema sexo-género fueron, por un lado, la "desnaturalización" de la sexualidad que ahora es vista como un sistema diferenciado del genérico pues son producto de campos diferentes de las prácticas sociales, no obstante que están organizados en el y por el mismo sistema de poder (Vance et al., 1989), y por otro, el reconocimiento de la conformación de las masculinidades.

El feminismo y las luchas lésbico-gays, como movimientos sexuales, han sido procesos muy importantes que conllevaron no sólo a modificar la vida sexual en general, sino replantearon la discusión tradicional sobre la sexualidad al cuestionar las relaciones de poder y dominación existentes sobre nuestras prácticas, elecciones e identidades sexuales, al exigir el derecho a su autodefinición, autodeterminación, legitimar su derecho de expresión y rescatar la diferencia como un valor. Sin duda alguna estos movimientos — en toda su diversidadhan contribuido notablemente al cuestionamiento de una moral sexual única basada en el esencialismo y determinismo —biológico, psíquico o social—y nos hace repensar la sexualidad resaltando su dimensión subjetiva, el pluralismo sexual y a la diversidad como norma cultural (op. cit., Weeks, 1998).

Para Anthony Giddens (1992), la sexualidad no es un conjunto de estímulos biológicos, ni una condición natural preestablecida; sino una elaboración social que opera dentro de los marcos de poder, "un aspecto maleable del yo, un punto de conexión primario entre el cuerpo, la auto-identidad y las normas sociales". El poder, desde su perspectiva, es generativo y también distributivo; crea realidades, administra y normativiza, y al mismo tiempo, es un fenómeno dialéctico donde existe la posibilidad — dada la reflexividad institucional— de provocar luchas con elementos emancipatorios, como es el caso de las mujeres. Es decir, las sociedades modernas están caracterizadas por el aumento de la reflexividad, lo que permite que hombres y mujeres jueguen un papel activo dentro del sistema social, teniendo nuevas oportunidades de organización.

Giddens sostiene que la represión sexual ha sido una cuestión de "secuestro social" asociado al poder genérico, que las transformaciones en la intimidad reclaman un cambio psicológico y por ende, cambios en la estructura social. La emancipación sexual la ve como un medio para reorganizar emocionalmente y de mejor manera la 


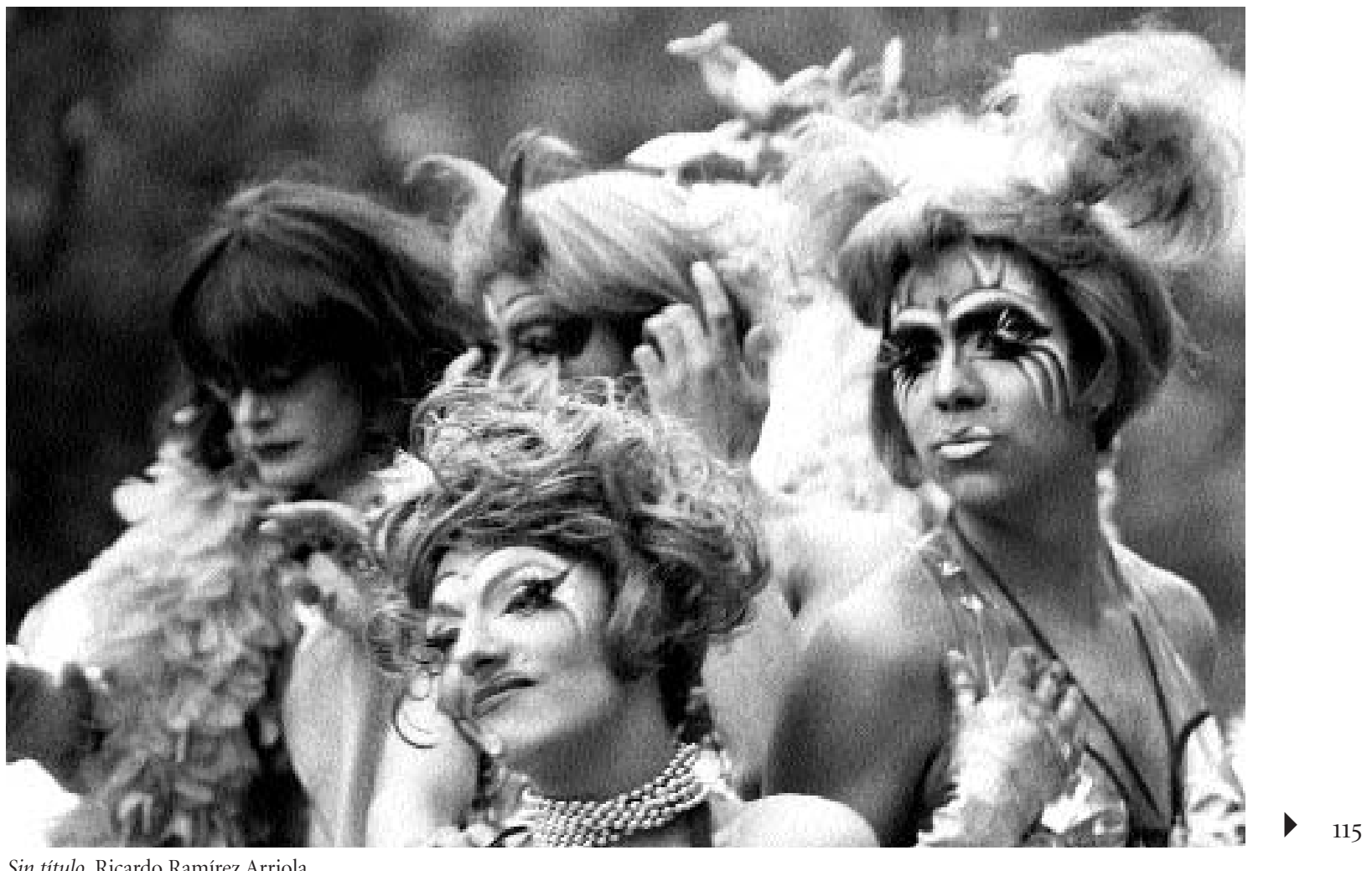

Sin título, Ricardo Ramírez Arriola

vida de los seres humanos, es "una forma de acción" para democratizar toda la vida personal, social e institucional. El punto nodal de las transformaciones se encuentra en la sexualidad y ésta sólo se puede desarrollar plenamente en "relacionamientos puros", caracterizados por la "reestructuración genérica” de la intimidad sexual femenina, el amor basado en la diferencia y en el conocimiento del otro, y el florecimiento del erotismo. El reencuentro de los sexos, el proyecto reflexivo del yo y "la sexualidad plástica" implican para el autor la promesa de la democracia, de ahí que su propuesta sea la pluralidad: ningún límite debe ser impuesto a la sexualidad, sólo aquéllos basados en el principio de autonomía y negociados al interior de la pareja, la cual no necesariamente tiene que ser monogámica ni heterosexual.

En este sentido, la polémica generada por la corriente constructivista sobre la sexualidad nos da la posibilidad de avanzar en varios supuestos esencialistas: $a$ ) la sexua- lidad no es una fuerza biológica o psicológica natural, autónoma, ahistórica y asocial que da forma a las instituciones, ni una "energía rebelde" que debe y puede ser moldeada y controlada; $b$ ) el fenómeno sexual no puede ser comprendido como un todo homogéneo y unificado, sino como una multiplicidad y variedad de formas que conllevan a la negación de la existencia de una sola historia sobre la sexualidad y el rescate de la diversidad de historias con características y singularidades propias, c) no hay maneras simplistas de analizar y comprender la organización social de la sexualidad; y d) dejar de ver la historia de la sexualidad como una lucha incesante entre represión y liberación - como planteaban Marcuse y Reich—, sino como "el resultado de distintas prácticas sociales que dan significado a las actividades humanas, de definiciones sociales y autodefiniciones, de luchas entre quienes tienen el poder para definir y reglamentar contra quienes se resisten. La sexualidad no es un hecho 
dado, es un producto de negociación, lucha y acciones humanas" (op. cit., Weeks, 1998: 30). Si para la "tradición sexual" la sexualidad es destino, para la corriente constructivista pasa a ser una construcción sociohistórica susceptible de ser transformada.

Tal vez valga la pena, que los antropólogos interesados en las investigaciones sobre las sexualidades hagamos nuestros los planteamientos de quienes manifiestan que el sexo no es ni bueno ni malo, sino simplemente un espacio de posibilidades y potencialidades que deben ser analizadas a la luz de las condiciones concretas en donde se manifiestan. Lo importante no es encontrar "la verdad trascendente", sino formas de tratar con "una multiplicidad de verdades", descartando la "moralidad basada en valores absolutos", reconociendo la necesidad de una "ética sexual moderna", en donde la diversidad sea la norma de nuestra cultura y un espacio para repensar las sexualidades (op. cit., Núñez, 1994).

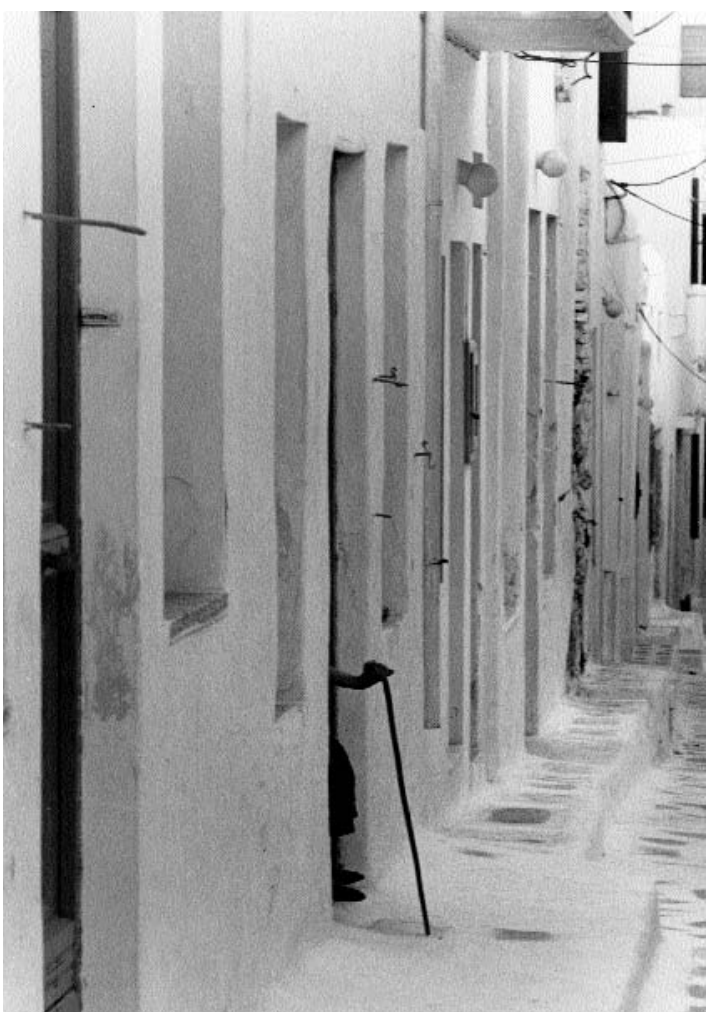

Al final, Jorge Acevedo
Este artículo tiene como objetivo mostrar cómo conciben, explican y ejercen sus relaciones amoroso-sexuales un grupo de pobladores de la costa veracruzana. Es un subproducto de mi tesis doctoral titulada Trabalho, poder e sexualidade: Histórias, valoraçoes e percepçoes femininas. Un estudo de caso na costa veracruzana, misma que desarrollé en un municipio del Golfo de México. Durante los once meses de trabajo de campo realicé un censo socioeconómico a 500 familias, lo que representa el 5 por ciento de la población; de la misma manera, apliqué 458 encuestas, de las cuales el 60 por ciento se hicieron con mujeres y 40 por ciento con hombres de entre 12 y 76 años, con diferentes niveles escolares (desde analfabetos hasta universitarios), oficios y profesiones. La intención era saber cuáles son las concepciones que tienen en torno al papel de los géneros al interior del matrimonio, la familia y la sociedad, y cuáles sus valores y prácticas sexuales. Finalmente, trabajé veinte historias de vida en donde hablan mujeres de la tercera edad, maduras, jóvenes y adolescentes; hay viudas, casadas, descasadas, madres solteras; todas tienen diferentes oficios: cocineras, trabajadoras sexuales, amas de casa, meseras y/o domésticas. Los hombres son pocos, una vez más se negaron a narrarme sus vivencias personales y familiares. No obstante que las historias son similares, cada uno le imprimió a su relato su experiencia personal única, subjetiva, enfatizando aquello que les dejó una marca a lo largo de su vida: el placer, la violencia, las drogas, el amor, el trabajo, los hijos...

\section{BOCA DEL CIELO ${ }^{1}$}

El municipio de Boca del Cielo se encuentra a diez metros sobre el nivel de la mar y su territorio es bañado por las aguas saladas del Golfo de México y las dulces del río Jamapa. Representa el 0.1 por ciento de la superficie total del estado de Veracruz, el 43.28 por ciento de terreno configura la mancha urbana y, según datos del INEGI,

${ }^{1}$ Nombre ficticio de la localidad donde realicé el trabajo de campo entre 1998-1999. 
tiene aproximadamente 135 mil habitantes, de los cuales el 52.5 por ciento son mujeres y 47.5 por ciento hombres. Los adolescentes —entre 10 y 19 años - representan el 30.2 por ciento de la población total, su tasa de crecimiento anual es de (-)1.2 y el 64.7 por ciento de sus pobladores laboran en el sector terciario.

La cabecera municipal, lugar que elegí para trabajar, no es un pueblo hermoso pero tiene su encanto, tal vez éste radique en que está enmarcado por el río y la mar. En general, es un lugar tranquilo, sin grandes manifestaciones de violencia, donde aún se puede caminar hasta altas horas de la noche sin correr ningún peligro. Sus habitantes (cerca de diez mil) son cálidos, albureros, ${ }^{2}$ fiesteros, bebedores, gritones y bailadores. Los hombres, los jarochos-boqueños, suelen ser guapos. Me encanta verlos pasar y apreciar lo maravilloso del mestizaje: negro, indio, español. Todos chirriscos, coquetos, galanes y con el don de la palabra amable, suave; se insinúan, pero no agreden... sólo esperan respuestas. Se quejan de sus mujeres, dicen que son infieles pero que seguramente es por la calor. ${ }^{3}$ Ellas, a su vez, reniegan de ellos, argumentan que son desobligados, borrachos y mujereros. La mayoría de ellas son hermosas, cuerpos voluptuosos que no niegan una raíz africana, rostros que reflejan mestizaje y andares que hablan de pasiones.

No obstante que sigue habiendo pescadores (oficialmente 164), la pesca se ha convertido en un arte de mera sobrevivencia. La contaminación de las aguas, la corrupción de las autoridades correspondientes, la modernización de las artes de pesca y la violación de las épocas de veda de las diferentes especies ha hecho que los peces huyan de la estupidez humana, se refugien en alta mar y se nieguen a seguir siendo el modo de vida de esta entidad veracruzana. Son indudablemente el turismo, la administración municipal y, en menor medida, el puerto de Veracruz (a través de la industria de la construcción, el acero, el transporte y el propio puerto) las fuentes principales de empleo para los boqueños. Los muchachos trabajan como meseros, cuidadores de autos, soneros,

\footnotetext{
${ }^{2}$ Aquél que acostumbra hablar con doble sentido.

${ }^{3}$ Las palabras en cursivas corresponden a vocablos o expresiones regionales.
}

vendedores ambulantes o bailarines en los afamados restaurantes de Boca, o bien se emplean en el palacio municipal como oficinistas, trabajadores de la limpia pública, choferes o jardineros. Las muchachas siguen la tradición laborando en tareas propias de mujeres, es decir, cocineras, meseras, domésticas, lavatrastes, cantineras o trabajadoras sexuales.

Para estos pobladores, Boca del Cielo es el lugar ideal para vivir. Se casan entre ellos, ahí nacen y crecen sus hijos, ahí entierran a sus muertos. Ahí siguen jugando la lotería, platicando, bebiendo y bailando en las esquinas. En fin, ahí transcurren lentamente sus vidas, entre el río y la mar, ésa que cuando es violenta es femenina y cuando está serena es masculina.

La sensualidad pareciera sazonar la vida cotidiana de esta población costera. Los bailes, el cuerpo, el lenguaje, la música, los versos, los albures, la comida, los olores y los chistes están impregnados de sensualidad. Como ellos mismos dicen: aquí, todo el día andamos con la cuca, la picha, la verga o el culo en la boca... es que el calor nos hace bramudos. Delante de los extraños cuidan su manera de hablar porque no quieren aparecer como ignorantes o groseros, pero conforme pasan los días y aumenta la confianza, el ambiente lúdico aflora y poco a poco se va haciendo común, "natural", escuchar ese lenguaje en constante juego con la sexualidad, en donde todo tiene doble sentido, connotación sexual: el chile, el elote, las picadas, la papaya, el chucumite, la salchicha, la micha, la torta, el torito, la cucaracha, el tamal, la garnacha, la empanada, el coyol, la guanábana, las tortillas, el mayate, el sancho, las pelotas, el mapache, el sapo, el koolaid...

No obstante que la mayoría de la población es católica, la religión no rige sus vidas; para ellos, la sexualidad forma parte de la naturaleza, pertenece al orden de lo natural pero no al divino. Con excepción del aborto, que para muchos es considerado un pecado, lo sexual es cosa de humanos y se concreta en cuerpos femeninos y masculinos. Nunca escuché a nadie hablar sobre lo bueno-malo, normal-anormal o pecaminoso cuando de sexualidad se trata.

Por las calles se oyen los gritos de los varones que hacen referencia a los órganos sexuales femeninos o masculinos: Ey tú, cara de... Las mujeres son más recatadas, 
lo que no implica que no usen dicho lenguaje entre ellas e incluso que algunas también les griten a los varones o a las personas con las que tienen problemas.

El bochorno cotidiano "obliga" a mostrar los cuerpos. La ropa es ligera, corta, suelta o ceñida pero siempre permite admirar los senos, las caderas, las cinturas, los genitales, las piernas, los brazos, y al caminar, los movimientos cadenciosos. Gustan decirse piropos, hacerse señas, rozarse, insinuarse, mirarse, provocarse, gritarse, mandarse besos o miradas pícaras. Los jóvenes casados, de cada uno de los sexos, también participan aunque con mayor discreción, cuidándose de las miradas de la suegra, la madre o los cónyuges, pero se las arreglan para no quedar fuera del ambiente lúdico colectivo. La playa es el lugar propicio para el encuentro amoroso o sexual, nadie posee un apartamento propio y pocos tienen dinero para pagar un motel; así, las parejas, no importando el sexo, se citan a la orilla de la mar para sexuar, ${ }^{4}$ lo que conlleva que buena parte del pueblo se entere quién se acuesta con quién, quién engaña a quién, quién es virgen y quién no, quién es choto, mayate, alocada o cuernudo, en fin, que la sexualidad se convierte en algo público y forma parte del día a día.

El calor hace que la mayoría de las puertas de las casas permanezcan abiertas por donde entran y salen amigos y vecinos buena parte del día y de la noche; la gente saca sus mecedoras o cobijas, ahí se sientan o acuestan a descansar, a jugar, a tomar, a recibir el fresco y a comentar la noticia del día. No existe la privacidad; conservar la intimidad o tener un secreto es muy difícil, de tal manera que todo mundo conoce los problemas de la familia de junto, los amoríos de los vecinos o las preferencias sexuales del amigo o pariente. Es común hablar con los otros, pero también de los otros, lo que permite comprender sus vivencias concretas y esperar recibir el mismo trato; ciertamente la opinión pública influye en sus comportamientos, pero al parecer, el no ocultar "la vida privada", el hacerla pública, les permite, de alguna manera, un efecto terapéutico, catártico, que termina por aceptación de los otros tal y como son.

\footnotetext{
${ }^{4}$ En lugar de utilizar el término popular de coger, decidí acuñar un nuevo verbo: sexuar, que significa tener relaciones sexuales.
}

En las fiestas pueden bailar mujeres con hombres, mujeres con mujeres e incluso se dan duelos entre varones; los movimientos son rítmicos, cadenciosos, muy sensuales; los cuerpos se rozan y suele haber una suerte de seducción entre las parejas. En las despedidas de solteras, aparte de llevar al striper que baila semidesnudo en honor de la futura esposa, todo el lugar está adornado con símbolos fálicos; las invitadas deberán beber colectivamente de un gran pene que hace las veces de vaso, el que posteriormente se pondrá en el centro y una por una, bailando, tendrán que simular la penetración ante la risa y los gritos de la concurrencia. Con la marcha nupcial de fondo, dos mujeres disfrazadas de novios (ella con grandes senos y nalgas de plástico y "él” con un enorme pene que le llega a las rodillas diseñado especialmente para la despedida con una media de nylon rellena con las trusas o calcetines del marido o los hijos) saludarán a todas; "él" ofrecerá en lugar de la mano, el pene.

Posteriormente, durante las seis o siete horas que dura la fiesta no se hará otra cosa que hablar, bailar y jugar con los diferentes penes (salchichas, palos, globos, condones rellenos de carne) que saldrán de cualquier bolso femenino. Al menor descuido le acercan el pene a la vagina, las nalgas, los senos o la boca de las mujeres que participan de la fiesta ante la risa incontenible de la mujerada que reclama a gritos: una picha por favor. Las mujeres no se tocan, no coquetean, no hay cachondeo entre ellas; no obstante que haya lesbianas, el erotismo se da en torno al pene: lo acarician, lo besan, simulan chuparlo, se lo meten a la boca, bailan con él, lo apapachan, lo abrazan.

Realmente se convierte en una catarsis colectiva en donde mujeres de todas las edades, en su mayoría abuelas de más de dos nietos, toman, fuman, gritan, ríen y bailan en honor al símbolo que les proporciona placer en algún momento de su vida. Al otro día, medio pueblo está enterado de lo sucedido y pasan días completos que no se habla de otra cosa que de la famosa despedida en la cual se toman fotos y circulan por todos lados ante la algarabía de hombres y mujeres que ríen a carcajadas y lamentan no poder haber asistido y haberse perdido la festividad. Nadie se enoja, sorprende o espanta.

Vale la pena mencionar la actitud que se asume en las reuniones con los homosexuales, los chotos como se 


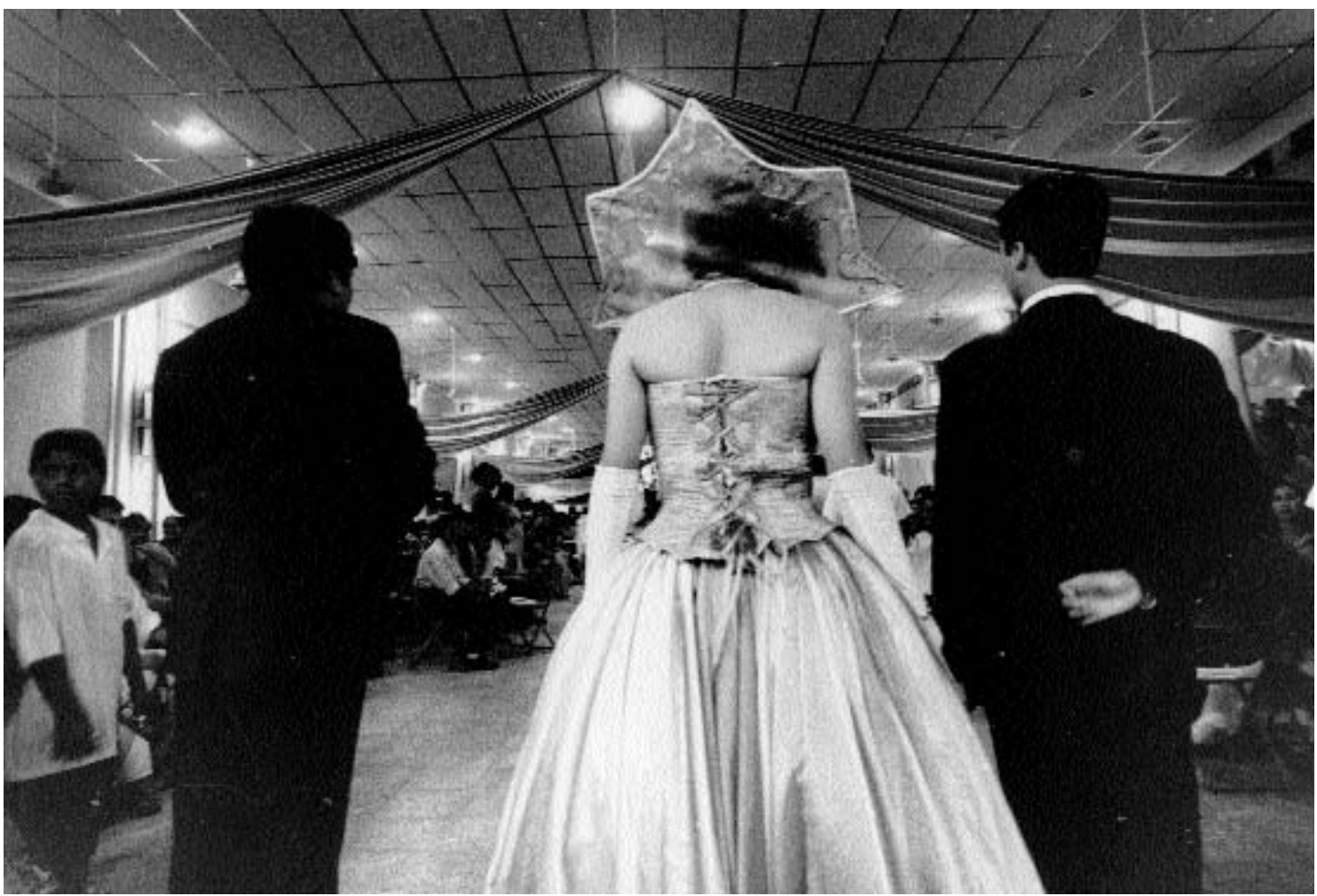

Chambelanes, Jorge Acevedo

autodenominan y les llama la gente del lugar, como parte de estos espacios donde todo está permitido pues forma parte del juego colectivo, son momentos de fiesta popular en los que se puede transgredir, momentáneamente, las normas socialmente establecidas. En las bodas, quince años o cumpleaños, los homosexuales del lugar son invitados porque son boqueños, ahí nacieron, conocen a sus abuelos y padres, los vieron crecer, son amigos que tienen derecho a participar en las celebraciones del pueblo.

Comparten la mesa con cualquier familia y conforme avanza la noche se van afeminando poco a poco, e inician el coqueteo con los hijos, esposos o hermanos de las mujeres de la mesa; le piden en matrimonio a los hijos o prestado al marido por un rato. Ellas bromean, ríen y de buena gana ceden a sus hombres; ellos les llaman por su nombre en femenino, les mandan besos y les prometen noches de pasión; los chotos sonríen pícaramente, les hacen ojitos y señas. Hombres y mujeres de alrededor también participan desde su mesa... hoy es de fiesta, se vale jugar y soñar colectivamente... mañana será otro día de trabajo, de violencia, de miseria, de escasez.

Lo anterior no implica que no haya normas que regulen y traten de controlar el ejercicio de la sexualidad. En el cotidiano así se vive, pero cuando uno se instala a hablar con hombres y mujeres sobre el tema, las cosas cambian rotundamente pues ellos mismos sostienen que de sexo no se habla, se hace. En general, es algo de lo que no les gusta hablar, se avergüenzan ante las preguntas directas, lo consideran algo íntimo que ni siquiera con la pareja se habla o discute. Con los hombres heterosexuales o bisexuales fue más difícil conversar abiertamente sobre la temática, no obstante los lazos de amistad y confianza logrados a través de los once meses de trabajo de campo; con las mujeres se logró mayor intimidad, pero fueron los varones homosexuales los que abiertamente 
hablaron sin ningún temor, incluso haciendo alarde de sus conquistas, detallando cuidadosamente sus gustos, posiciones y preferencias eróticas.

\section{SEXUALIDADES, GÉNEROY GENERACIONES}

Existe una división diferenciada de la sexualidad entre hombres y mujeres. Ambos reconocen que el deseo sexual puede ser experimentado por ellos porque forma parte de la naturaleza humana y en esa medida es concebido como una necesidad, pero consideran que las mujeres deben controlarlo por respeto al hombre y a los hijos, que deben ser recatadas porque socialmente pierden más. Ellas son educadas para ser dependientes y cumplir con los requerimientos de los varones, las normas

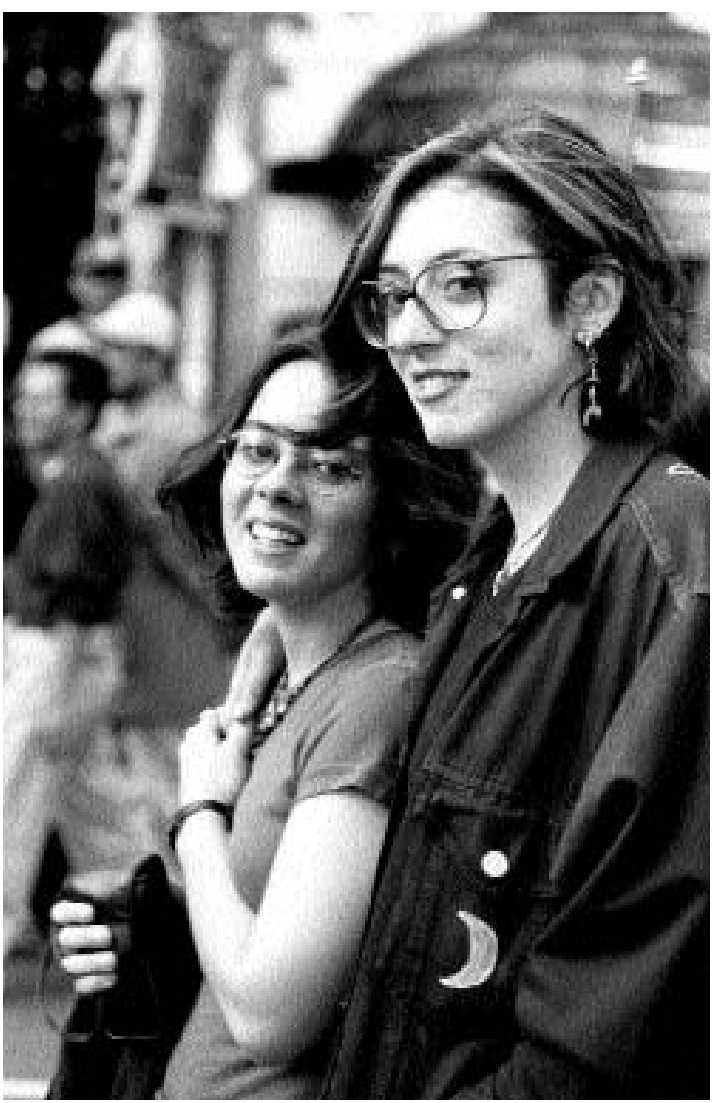

Sin título, Ricardo Ramírez Arriola establecen que deben llegar vírgenes al matrimonio, ser iniciadas sexualmente por sus maridos, cumplir con el débito conyugal, esperar que el marido tome la iniciativa y, si es necesario, fingir para retenerlo; no les debe gustar sexuar demasiado y tampoco ejercer su sexualidad de manera desinhibida ni diversa. Se les insiste que la maternidad es el referente principal de la identidad femenina, por lo que la sexualidad debe estar ligada a la reproducción y no al erotismo; se les enseña que el cuerpo sirve para dar hijos y servicio a sus cónyuges, pero no que es una fuente de placer que les permite dar y recibir sensaciones eróticas. La sexualidad personal, espontánea y placentera es motivo de vergüenza y sospecha. Las mujeres deben ser, ante todo, abnegadas madres y fieles esposas.

Por su parte, la sexualidad masculina es reconocida como un proceso biológico, natural, instintivo y por lo tanto desbordante, inevitable e incontrolable porque pertenece al orden del deseo; a través de su ejercicio se demuestra la hombría y se logra la identidad genérica. Aunque se reconoce que la fidelidad es un valor que ambos cónyuges deben respetar ( 85 por ciento de la muestra lo señala), también sostienen que para los hombres es imposible cumplir con esta regla pues ellos son de la calle, su naturaleza es más caliente y se excitan más rápido ( 55 por ciento). Ellos tienen permiso social para ejercer su sexualidad de manera menos reprimida: se les incita a hacerlo llegada la adolescencia, tienen libertad para elegir diversos cuerpos en diferentes espacios, de variadas maneras y posiciones. Una de las limitaciones que se les impone es que con sus esposas, con la madre de sus hijos, no se deben tener relaciones sexuales ofensivas, otros tipos de sexos (oral y anal) porque es una falta de respeto; para eso están las otras: las trabajadoras sexuales, las queridas, las chamacas alocadas y los chotos; así, su infidelidad queda justificada. La sexualidad masculina es algo que se deja correr libremente, mientras que la femenina es necesario controlar y normar.

Dentro de la sociedad local, el papel de las mujeres ha sido culturalmente establecido dentro del matrimonio y el hogar, para garantizar esto se les educa como guardianas de la moral y la honra familiar. La valoración social de lo femenino se basa en el binomio conyugalidad-maternidad (7o por ciento considera que lo más importante 
en la vida de una mujer son el marido y los hijos y, el 75 por ciento que el matrimonio le da felicidad y seguridad). El conjunto de normas y valores les prohibe el ejercicio libre de la sexualidad, aceptado solamente ligado a la maternidad. Las relaciones sexuales están permitidas sólo dentro del matrimonio, son las señoras casadas las que pueden sexuar para convertirse en madres o cumplir con las necesidades naturales de sus maridos. Las adolescentes no tienen derecho a ejercer su libertad sexual so pena de ser consideradas como bramudas, calenturientas, es decir, mujeres que muestran una actitud de disfrute sexual, que transgreden los límites impuestos socialmente y se permiten el derecho al placer, al gozo, al erotismo. En nuestro estudio hemos registrado que las adolescentes que tienen relaciones sexuales prematrimoniales generalmente lo niegan porque saben que están transgrediendo las normas establecidas; es mejor aceptada una madre soltera que una adolescente que planea sus relaciones sexuales usando anticonceptivos. Consideran que el hecho de planear es premeditar y esto es algo indebido; los anticonceptivos están orientados para mujeres casadas con hijos, es decir, sólo a ellas se les permite separar reproducción de sexualidad, usarlos fuera del matrimonio está asociado a conductas sexuales ocasionales y con mujeres que el ideal femenino debe evitar.

Cuando hablamos de sexualidad en Boca del Cielo no podemos hacer generalizaciones, si acaso registrar ciertas tendencias logradas a través del análisis del discurso. No obstante que mujeres y varones de diferentes edades, escolaridad, estado civil y ocupaciones expresaron, por medio de las encuestas, entrevistas e historias de vida un discurso bastante homogéneo, a veces "tradicional" y a veces "liberal”, sus comportamientos y prácticas sexuales nos hablan de un desfase entre los códigos morales (civiles o religiosos) impuestos como el ideal a seguir y la vivencia cotidiana que se refleja en una gran diversidad que muchas veces atraviesa las generaciones, los géneros y los grupos sociales.

Como tendencias podemos decir que la población encuestada no acepta las relaciones sexuales prematrimoniales ni en mujeres ( 70 por ciento) ni en varones ( 53 por ciento), aunque casi la mitad niega la importancia de la virginidad femenina al reconocer que el valor de una mujer no depende de ella. El 55 por ciento reconoce que cada uno de los sexos tiene necesidad de sexuar, aunque también el 55 por ciento considera que el deseo masculino es mayor. El 80 por ciento de hombres y el 53 por ciento de las mujeres reconocen que les gusta tener relaciones sexuales, que éstas les causan placer (70 por ciento de los primeros y 43 por ciento de las segundas) y que no las ejercen sin tener ganas (68 por ciento y 79 por ciento respectivamente). Sostienen que es correcto que la mujer busque el encuentro sexual con su marido (el 54 por ciento de los varones y el 51 por ciento de las mujeres), que ésta no debe fingir placer para retenerlo (79 por ciento masculinos y 67 por ciento femeninos), que la menopausia no acaba con el deseo ( 45 contra 51 por ciento) y que se pueden tener relaciones sexuales durante del embarazo ( 56 y 62 por ciento respectivamente).

Hay un rotundo sí a la fidelidad masculina (8o por ciento) y femenina ( 87 por ciento) y un rotundo no al aborto $(68$ por ciento de los varones y 75 por ciento de las mujeres). El 58 por ciento de los hombres aceptan la práctica de la masturbación, mientras que las mujeres se encuentran divididas pues el 33 por ciento dice que sí, el 39 por ciento dice que no y el 29 por ciento ignora; solamente un 30 por ciento de la muestra está de acuerdo en que la homosexualidad debe ser permitida (el 31 por ciento de los varones y el 30 por ciento de mujeres).

Existe, en el discurso, una aceptación sobre la necesidad de separar reproducción de sexualidad (99 por ciento); sobre el uso de anticonceptivos (87 por ciento) incluyendo los masculinos (condón, 57 por ciento, y vasectomía, 67 por ciento), aunque hay mayor reticencia del lado masculino ya que sólo el 50 por ciento de ellos está de acuerdo en usar condón y un 48 por ciento en hacerse la vasectomía, a diferencia de las mujeres, de las cuales el 62 por ciento acepta el uso del primer método y el 77 por ciento del segundo.

\section{LAS MUJERES}

En nuestro universo de estudio, a lo largo de la historia, ha habido mujeres que han reproducido y transgredido normas como parte de un mismo proceso, no existen 
rupturas abismales entre las generaciones, hablamos de un continuum generacional donde posiblemente podemos observar énfasis diferentes de continuidad, cambios o transgresiones. Así por ejemplo, encontramos que entre mujeres de una misma generación (las abuelas), unas simplemente cumplieron fielmente con los requerimientos impuestos por el débito conyugal y la procreación mientras que otras disfrutaron su erotismo; algunas, al entrar en la menopausia, dieron por terminada su vida sexual dedicándose al cuidado de los nietos, y para otras significó el inicio de una vida sexual plena al no temer por un embarazo no deseado; algunas se separaron y se volvieron a casar, otras conservaron su matrimonio y tuvieron amantes ocasionales.

Muchas de las madres permanecieron fieles, dependientes y sumisas a los caprichos, infidelidades y maltratos de sus maridos, pero otras optaron por el trabajo extradoméstico logrando cierta independencia económica, libertad de movimientos e incluso estableciendo relaciones sexuales extramatrimoniales en donde la búsqueda del placer y la satisfacción de sus deseos fue la constante. Igualmente observamos esta situación entre las hijas, las adolescentes de hoy, para quienes la virginidad sigue siendo el ideal a alcanzar ( 52 por ciento) pero difícilmente logrado porque les gana el gusto $;^{5}$ unas disfrutan de su vida sexual con su cónyuge, algunas buscan la satisfacción sexual discretamente fuera de casa, otras lo hacen a fuerzas (sólo el 16 por ciento declaró sexuar bajo estas circunstancias) porque consideran que es parte de sus obligaciones como mujeres casadas, hay quienes se atreven y se niegan a tener relaciones sexuales sin tener ganas ( 83 por ciento de las mujeres), no faltan las que simplemente se conforman con que el acto sexual se convierta en algo rápido y lo menos frecuente posible, y finalmente, hay quienes son violadas.

No pocas se divorcian, regalan a los hijos y se buscan un nuevo hombre o simplemente optan por el trabajo sexual como una manera de mantener a su prole, o deciden quedarse solas con los hijos y sólo tienen relacionamientos

\footnotetext{
${ }^{5}$ Expresión local que se refiere a la necesidad que manifiestan algunas jóvenes por tener relaciones sexuales.
}

ocasionales que les proporcionan ayuda económica y, fundamentalmente, satisfacción sexual. Y existen las de siempre, las que se conforman, por el bien de los hijos, con un marido que las mantenga y no las golpee, aunque sea mujeriego y borracho, procurando tenerlo contento en la cama para retenerlo, fingiendo que obtienen placer (el 61 por ciento de ellas lo niega); es decir, usan su cuerpo para poder negociar, canalizando su erotismo hacia el amor maternal.

No hay un solo patrón de comportamiento. No todas ni siempre, reproducen, asumen, transgreden o transforman. Ciertamente existen constantes, y tal vez una de las más importantes sea el desconocimiento sobre su cuerpo y la sexualidad, pues si bien es cierto que hoy en las escuelas se dan clases de "educación sexual", éstas no rebasan los límites de la fisiología reproductiva, la descripción de los "órganos reproductores", la anatomía de los sexos y los procesos biológicos sobre la menstruación, el embarazo y el parto, en donde el cuerpo es neutro, sin género. Muchos adolescentes, sin importar el sexo, cursando el tercero de secundaria, cuando se les preguntó su opinión sobre la virginidad, la menopausia, el homoerotismo o la masturbación, respondieron que no sabían qué era eso y, aunque la mayoría dijo estar de acuerdo con el uso de anticonceptivos, al mismo tiempo comentaron que en su momento no sabrían cuál usar.

Padres y madres siguen sin platicar con sus hijos sobre sexo, éste sigue siendo un tabú dentro de la familia; consideran que la escuela y la televisión ofrece suficiente información para que los chamacos ya no anden con los ojos cerrados como antes les sucedió a ellos. La mayoría de las madres ni siquiera les comenta a sus hijas que van a menstruar, mucho menos qué va a suceder cuando tengan relaciones sexuales; lo que tienen claro las adolescentes es que deben conservar su virginidad, pero esto no forma parte de pláticas o discusiones formales, los comentarios son descontextuados, cortos y simples: no dejes que tu novio te toque de la cintura pa'bajo, no me vayas a salir panzona porque tu padre me mata, la pureza es importante para que puedas vestirte de blanco en el día de tu boda, o si quieres tener un buen matrimonio y un hombre que te respete, cuídate. A los varones no se les dice nada, por el contrario, cuando entran a la pubertad se 


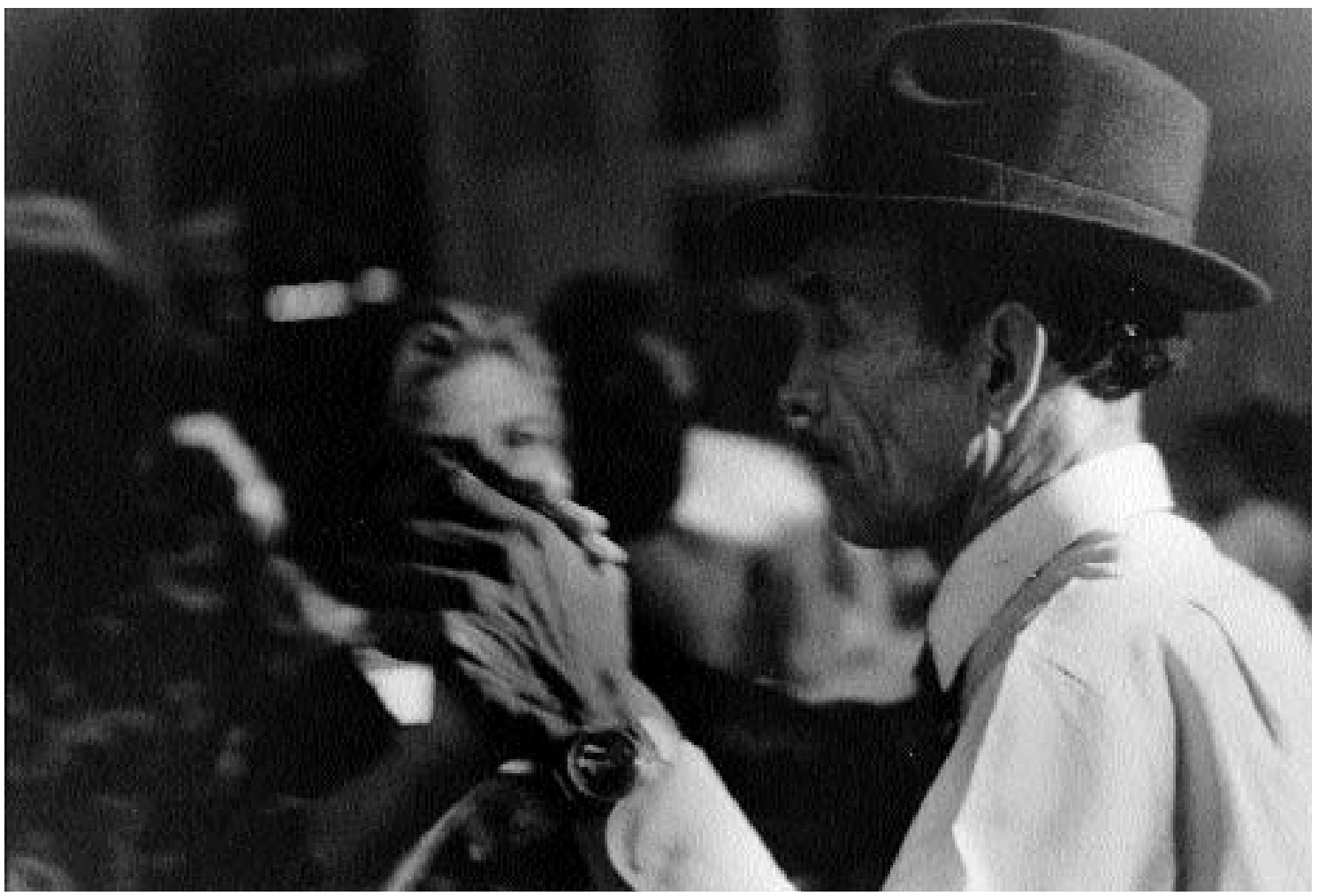

Danzón II, Jorge Acevedo

festeja que ya se les para, que ya ande correteando a las gallinas, en el entendido que si la novia queda embarazada será culpa de sus padres por no saberla cuidar, y de ella misma pues el hombre llega hasta donde la mujer quiere.

No obstante, que la muestra resalta que el 47 por ciento de la población encuestada dijo que no es importante que la mujer llegue virgen al matrimonio, y otro 47 por ciento se manifestó a favor, el 80 por ciento coincidió que el no llegar no le resta valor. Por supuesto, que ayer como hoy, son muy pocas las mujeres que llegan vírgenes a su primera unión y buena parte de ellas lleva un hijo en su vientre. Las boqueñas, en general, inician su vida sexual siendo muy jóvenes, no obstante las recomendaciones maternas y, en algunos casos, las amenazas paternas. Confiesan que se acostaron con sus novios por bramudas, no por amor, sino simplemente porque les ganó el gusto; muchas ni siquiera han empezado a menstruar y esto les permite librarse de un embarazo durante los primeros meses, después quedan a la buena suerte, celebrando con el novio que por ese mes vimos la mestruación, hasta que inevitablemente salen embarazadas y tienen que enfrentar a los padres, el matrimonio y la maternidad forzada. Además de que no están de acuerdo con la legalización del aborto, éste no representa una opción por carecer de contactos y recursos para practicárselo (lo que no implica que no existan las excepciones); así el embarazo y la maternidad se convierten en un poderoso determinante social de la condición femenina.

Las abuelas cuentan que no sabían exactamente qué iba a suceder en su primer encuentro sexual; las madres y las hijas, al menos en teoría, tenían una idea de lo que iba a acontecer. Casi siempre, sin importar la generación, los primeros encuentros sexuales de las mujeres son descritos como dolorosos, hay temor, miedo, susto y es el compañero quien le enseña cómo sexuar; pero pasados los primeros días se habla del disfrute, del gusto (89 por 
ciento), de la aceptación de las relaciones sexuales durante el embarazo ( 81 por ciento), y de la diversidad de caricias ( 45 por ciento), incluso de la búsqueda del compañero para obtener placer (69 por ciento).

El cambio viene con el tiempo, argumentan que mientras fueron novias o estuvieron solas, sin hijos, su relación sexual fue placentera, después se desencantaron porque los hombres no cumplieron con sus expectativas, sobre todo económicas, y se volvieron irresponsables, borrachos, mujereros, violentos, y a ellas se les acabó el amor, se les murió el gusto, sólo queda el hartazgo, el cansancio y la obligación de cumplir en la cama con el marido por diversas razones: para tenerlo contento, para evitarse problemas, para negociar, por obligación, para obtener prebendas. Difícilmente se dan conversaciones en torno a los gustos y necesidades personales de cada miembro de la pareja, el sexo es un tabú del cual no se habla ni en la alcoba.

Ciertamente que con el marido es difícil establecer relaciones eróticas, pero esto no implica que las mujeres casadas no reconozcan y hablen de su necesidad sexual (73 por ciento), de las ganas de tener un hombre que las satisfaga, de la posibilidad de gozar y vibrar en sus brazos (8o por ciento). No se conforman vivir en el cotidiano sin placer y lo buscan, sea rompiendo definitivamente con el marido, sea en encuentros ocasionales o bien, con un amante de planta pero discreto (40 por ciento).

Hay quienes asumen el abuelaje — que muchas veces coincide con la menopausia, alrededor de los 40-45 añoscomo la última etapa de su vida en donde ellas ya no tienen derecho a tener aspiraciones, necesidades o deseos propios — si es que alguna vez los tuvieron—; se deben principalmente a los nietos y su vida gira a su alrededor pues muchas veces dependen de ellas ante el abandono de sus progenitores. Para ciertas mujeres, la menopausia está unida al fin de su vida sexual pues consideran que ya no tienen edad para esas cosas, su tiempo ya pasó y ahora viene el de los nietos; pero otras (58 por ciento) Comentan que es el momento en el que más disfrutan su

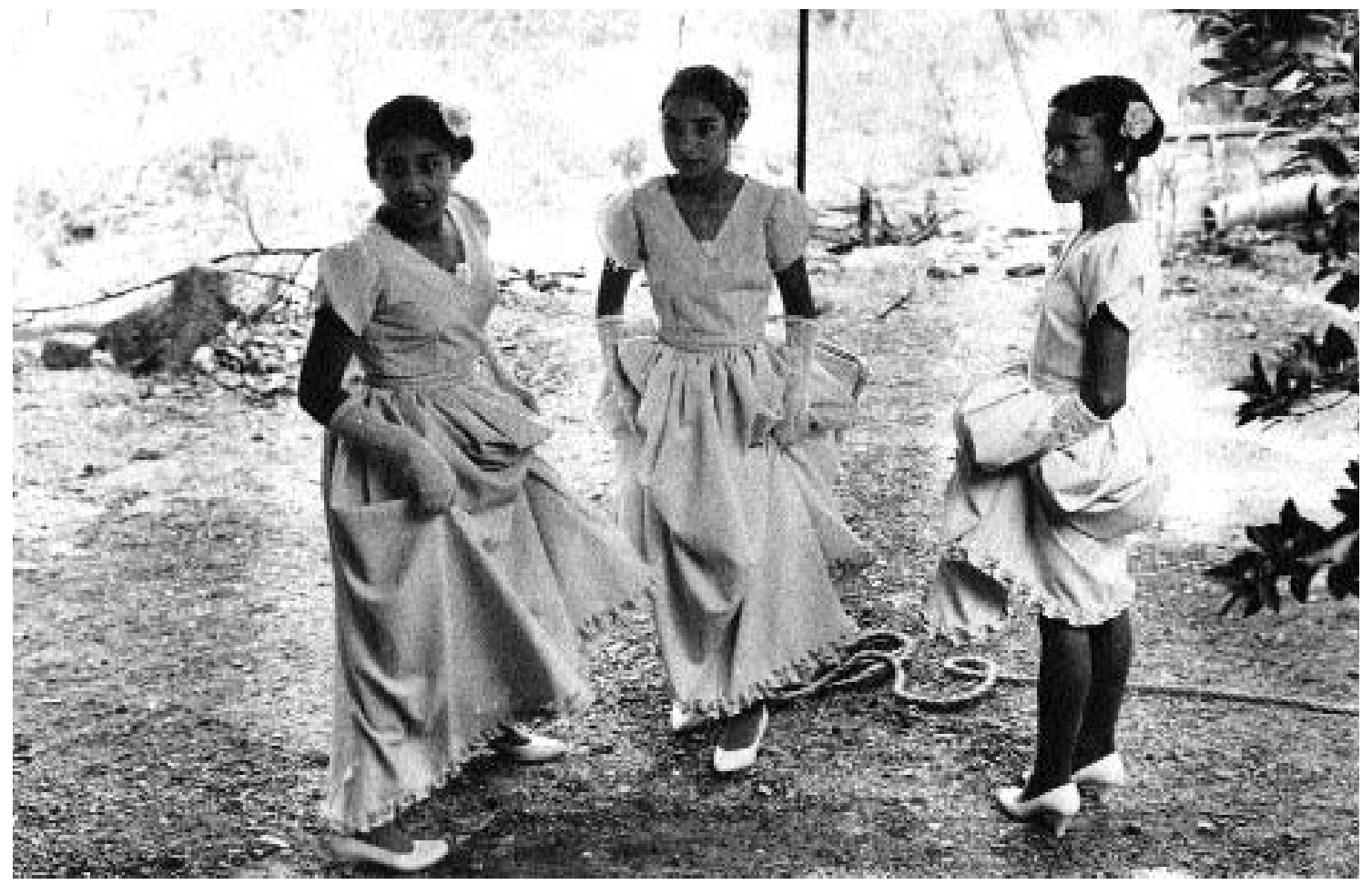

Antes de la .... Jorge Acevedo 
erotismo porque ya no hay posibilidad de embarazarse, los hijos ya están grandes y la brama se le alborota a uno. Las casadas gozan con sus esposos; las separadas, divorciadas o viudas buscan un hombre sin compromisos que les pueda cumplir y satisfaga sus fantasías.

Cuando se reúnen las amigas y alguna de ellas confiesa que hace mucho no sabe lo que es un hombre, la mujerada le insiste en que es muy importante que satisfaga esas necesidades que el cuerpo le reclama porque, de lo contrario, le puede ocasionar graves daños a su salú física y mental. Total, para comer carne no tienes que tener carnicería, te metes al monte matas un conejo, dejas tirada la piel y nadie se dio cuenta... A estas alturas de la vida sus códigos morales están mucho más relajados y se permiten ejercer una sexualidad más libre, diversa y placentera. Hacen caso omiso de las críticas de los hijos, hijas, nueras, yernos y demás familiares, y aprovechan sus años maduros para reponerse del disfrute sexual que durante los años de matrimonio les estuvo negado.

Las mujeres pocas veces hablan del enamoramiento o el amor, y cuando uno hace referencia al tema no saben exactamente cómo definirlo (sin embargo, el 81 por ciento considera, al igual que los varones, que el amor es más importante que el placer); no obstante, está asociado a demostraciones de ternura, de regalos personales o de bienes materiales. Que un hombre las quiera significa que no las maltrate ni las ofenda, que les haga una caricia o les dé un beso, que les regale un perfume, un vestido; que les compre una video, una televisión o una casa. Hacer el amor es diferente, esto está vinculado con la pasión, con el placer, con la brama, es decir, con una fuerza interna, con un impulso que recorre su cuerpo y las incita a sexuar. Cuando le pedí a una señora de 75 años que me definiera qué era la brama me respondió que bien a bien no lo sabía, pero que es algo que nos da a todos: al gobernador, al cura, a viejos, jóvenes, mujeres y hombres; ante mi insistencia se quedó pensativa por un momento y después me respondió: Mira m’ija, la brama es un calor que te empieza por las patas, poco a poco te va subiendo, y cuando te llega al culo perdiste la decencia.

Como podemos observar, no obstante los valores morales, los controles sociales y los silencios familiares que se establecen en torno al cuerpo, la sexualidad y sus placeres -mismos que los pobladores boqueños los repiten a través del discurso- el énfasis de las mujeres está puesto en las relaciones sexuales placenteras incluso más allá de la experiencia amorosa. Fuera de la esfera conyugal aceptan la diversidad de posiciones, caricias, demuestran su deseo, solicitan la satisfacción de sus fantasías; la práctica antigua (desde hace 36 años) y generalizada de la salpingoclasia (el 65 por ciento de las mujeres de la muestra optaron por este método definitivo de manera voluntaria) permite a casadas, separadas, divorciadas o viudas la espontaneidad de los encuentros. A las mujeres, no importando la edad, les gusta tener relaciones sexuales cuando han descubierto que les produce placer y no renuncian a los goces del cuerpo.

\section{HETEROSEXUALES MASCULINOS}

A los varones les costó más trabajo definir el amor o el enamoramiento. El amor es el amor, respondió la mayoría, tan sólo uno me alcanzó a decir: tú sabes que estás enamorao cuando sientes algo muy bonito por alguien. Que una mujer los ame significa que sea una excelente ama de casa, una cuidadosa y abnegada madre, una obediente, fiel y atenta esposa que cubra todas sus necesidades: comida caliente, ropa limpia y planchada, casa ordenada, hijos bien educados. Menos aún que las mujeres, el amor lo asocian con la sexualidad, a ellos cualquier chava cachonda o buenona los excita y esto es suficiente para acostarse con ella y disfrutar el momento de pasión sin pensar en las consecuencias posteriores.

Idealmente, los hombres las prefieren vírgenes (46 por ciento), pero al igual que las mujeres saben que esto es muy difícil de cumplir, por lo que sostienen ( 78 por ciento) que el no llegar vírgenes no les resta valor. Ciertamente no les gustan las mujeres alocadas, fáciles, bramudas, es decir, aquellas que ejercen su sexualidad de manera abierta y diversa, pues consideran que tienen una reputación dudosa al saber que se han relacionado sexualmente con varios hombres del pueblo: ellas si acaso sirven para un momento de placer. No obstante que muchos adolescentes se inician sexualmente con las trabajadoras sexuales o los homosexuales del lugar, posteriormente es 
común que mantengan relaciones sexuales con sus novias, con las que generalmente se casan, y para las cuales no tienen reclamos, siempre y cuando ellos hayan sido la primera y única pareja sexual. Existen jóvenes que se unen con mujeres que no son vírgenes sin que esto tenga consecuencias en su vida como pareja; otros las aceptan pero en los momentos de conflicto, sobre todo cuando media el alcohol, se le reclama que haya sido una chamaca loca que perdió su virginidad en brazos de otro hombre, $\mathrm{y}$ algunos justifican la violencia física, psicológica y verbal por esta razón.

Con la esposa tienen relaciones sexuales para tener hijos o para satisfacer las necesidades naturales de ambos, principalmente las suyas y, la posición para sexuar debe ser la natural, es decir, las relaciones vaginales en la posición tradicional del misionero. Sin embargo, en el discurso reconocen que la mujer debe buscar el encuentro sexual (86 por ciento), que no debe fingir placer para retenerlos ( 83 por ciento) y que se pueden experimentar diversos tipos de caricias (6o por ciento). Saben que deben ser fieles (8o por ciento) por respeto a la esposa, para evitarse problemas, para seguir juntos, pero al mismo tiempo reconocen que tienen licencia social para ser infieles y que, comúnmente, lo son. Suelen ser discretos, pero el pueblo es tan pequeño que finalmente todos, incluida la mujer, se acaban enterando; este es un hecho que no conlleva la separación de la pareja, las mujeres asumen que por naturaleza todos los hombres son así y evitan confrontar la situación con la esperanza de que $e l$ enculamiento les pase rápido.

Cuando la infiel es la mujer y es descubierta, entonces sí es causal de violencia, algunas veces de divorcio, y el pueblo entero, incluyendo a las propias mujeres ( 85 contra el 90 por ciento de los varones) justifican el rechazo social y la violencia.

Los varones casados recurren a las cantineras y/o trabajadoras sexuales y a los homosexuales, o bien, se hacen de una querida con la que fundamentalmente satisfacen sus fantasías eróticas; es en estos espacios en donde la sexualidad está vinculada al placer porque tienen la posibilidad de experimentar todo tipo de caricias y posiciones posibles que están negados a realizar con la madre de sus hijos.
Igual que las mujeres, los hombres reconocen que durante la etapa del noviazgo y los primeros tiempos del matrimonio tuvieron una vida sexual satisfactoria con su pareja, después igualmente llegó el hartazgo, el cotidiano, la insatisfacción, los hijos; muchos sostienen que con los embarazos uno pierde a su mujer, se vuelven madres y se olvidan que tienen marido. Son pocos los que tienen un vida erótica con su esposa, la mayoría reclama el débito conyugal, protesta cuando se niegan a cumplirlo pues consideran que es parte de las obligaciones que las mujeres contraen con el matrimonio. Unos les exigen, otros las obligan, hay quienes las violan; otros, les lanzan acusaciones de que no se acuestan con ellos porque seguramente andan con otros hombres; no falta quien, ante la negativa, airosamente les grita que por eso tiene una querida, porque ella ni como mujer le sirve.

Aunque el 51 por ciento declaró que la vida de casado es mejor que la de soltero, la mayoría se casó ante un embarazo imprevisto, no por amor o pasión, por lo que rápidamente se cansan del matrimonio, de la mujer y los hijos. La madre de ellos presiona para que se mantenga el matrimonio argumentando el bienestar de los nietos; hay quien hace caso omiso de estos argumentos y simplemente abandona a su familia, pero no es lo común, buena parte de ellos mantienen la unión porque fueron hijos sin padre presente o de padre ausente y no quieren que sus descendientes sufran lo mismo, o bien, consideran que su esposa es una buena madre y carecen de argumentos para dejarla. Así quedan atrapados en relaciones a veces violentas $\mathrm{y} / \mathrm{o}$ poco afectivas $\mathrm{y}$, al igual que sus mujeres, van cumpliendo con sus obligaciones conyugales. Nunca falta una mujer con la que puedan realizar sus sueños eróticos.

\section{PODERES FEMENINOS-TEMORES MASCULINOS}

No pretendo negar la subordinación femenina, pero seguir insistiendo en que los hombres se pusieron de acuerdo para dominar a la mitad de la especie humana - lográndolo en todas las culturas por cerca de cinco mil años- nos ofrece una imagen bastante devaluada de 
nosotras mismas y nos remite a explicaciones bipolares en donde las mujeres aparecen como eternas víctimas o luchadoras incansables. Es necesario remarcar que la realidad es mucho más compleja y contradictoria, y reconocer, por un lado, que existe diversidad y vulnerabilidad masculina y, por el otro, que las mujeres, a lo largo de los procesos históricos y de nuestra propia historia, hemos tenido espacios de poder que nos han permitido influir y contribuir para crear las diversas estructuras socioculturales, incluyendo "el patriarcado" y el sistema social sexista. Las madres y las suegras, al ejercer la autoridad dentro de la esfera doméstica haciendo respetar las desigualdades genéricas, reproducen el orden social dominante; así, desafortunadamente, la reproducción del sistema sexo-género, al igual que el dominio masculino, está garantizado por la acción de las propias mujeres.

El poder femenino ha variado a lo largo de la historia; como bien sostiene Linda Gordon (1992), no hay experiencias femeninas carentes de poder, ser menos poderosas no significa carecer de él ni perder siempre. Una cosa es hacer conscientes las relaciones jerárquicas y de subordinación en las que están inmersas como género, y otra asumirse como víctimas. Esto impide, por un lado, reconocerse como actoras sociales capaces de transformar la realidad; por otro, perder de vista aquellos espacios concretos y específicos que logran transformar y reclasificar, simbólicamente, a través de la práctica, y finalmente, negar las variadas estrategias que desarrollan para enfrentar la asimetría, logrando áreas de poder femenino.

Desde mi punto de vista, uno de estos espacios lo constituye nuestro propio cuerpo tan desconocido, misterioso y temido por los hombres por ser un instrumento que posibilita la vida y el placer. De él emanan parte de nuestros poderes y misterios que se relacionan con lo fisiológico y con lo subjetivo: la menstruación, el embarazo, el parto, la maternidad, la seducción, el ejercicio de la sexualidad, el placer y los saberes femeninos ligados a ritos, mitos y hechicerías.

En Boca del Cielo, el ámbito doméstico, tradicionalmente considerado femenino, dominado por mujeres, se convierte en el espacio que les permite generar y desarrollar "los contrapoderes", herramientas y estrategias de resistencia, dominación, control y manipulación, cuyo

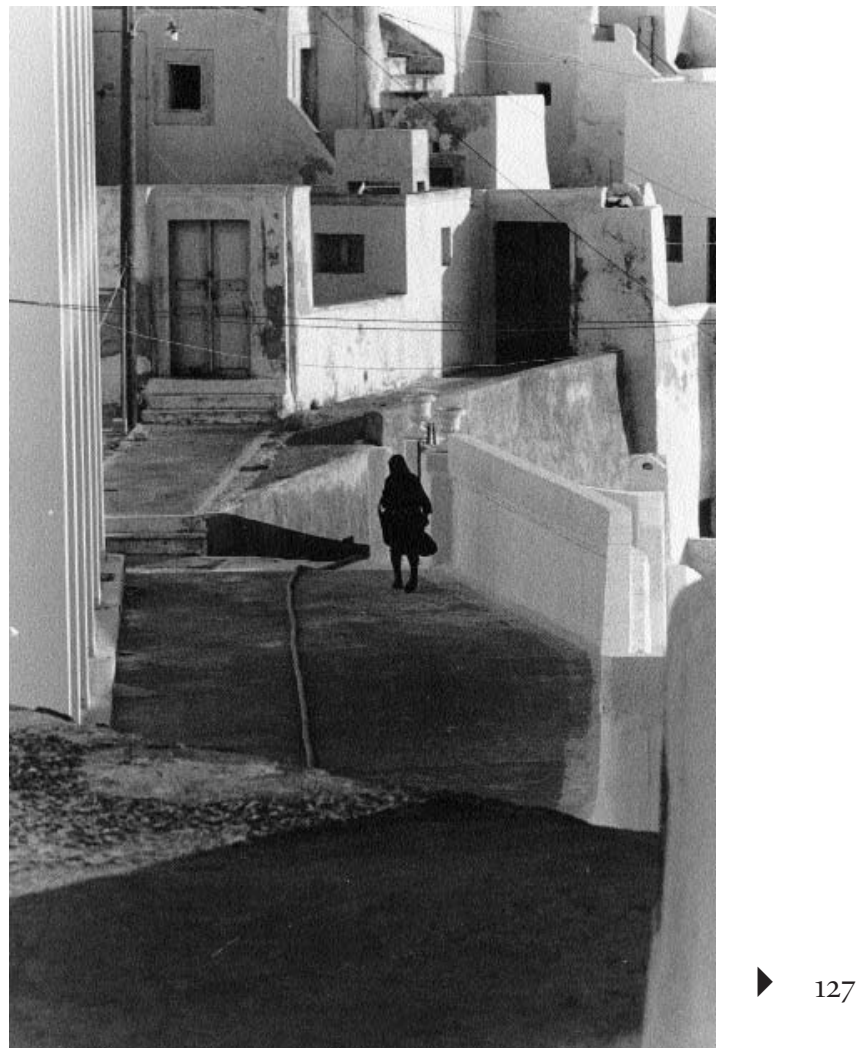

Solitaria, Jorge Acevedo

objetivo es trastocar el orden al que son sometidas. Ahí, las mujeres se reúnen para transmitirse los saberes femeninos adquiridos a través de largos años: recetas de pócimas, tés, brebajes, yerbas u oraciones en las que confían, a pie juntillas, y no dudan en poner en práctica para conseguir sus objetivos: someter al hombre a su voluntad. Los deseos son variados: obligarlo a casarse, serle infiel sin que lo note, separarlo de la querida, volver estéril o hacer abortar a la amante, alejarlo de la madre, obtener un hijo varón, y dado el caso, volverlo impotente, temporalmente, para que no la siga engañando. De ahí que la reunión solidaria de las mujeres no guste al sexo masculino ni a las propias suegras; las otras, las amigas, las cuñadas, las suegras, no son dignas de confianza de los hombres casados porque les dan malas ideas y pensamientos, ellas no se juntan para nada bueno, suelen decir los boqueños y sus madres. 
Pero las mujeres no solamente usan pócimas; desde niñas las han socializado en el uso del cuerpo para la seducción y están conscientes de que, a través de él, pueden obtener ciertos logros, aunque en algunos casos, a la larga les resultan contraproducentes. Mientras tanto, se embarazan para lograr un matrimonio aunque sea forzado o para tratar de retener al marido que anda con otra mujer; así mismo usan los nueve meses del embarazo para chantajear o manipular al esposo. El cuerpo también es utilizado vía genital, fundamentalmente, para tenerlo contento y en paz y poder negociar prebendas: permisos, regalos, dinero, paseos o lograr alianzas en contra de las suegras y las amantes. No nos debe extrañar pues, que las mujeres boqueñas utilicen su sexualidad y maternidad como espacios de sobrevivencia y resistencia, como estrategias de poder donde se transgrede lo masculino y se generan identidades contradictorias.

En Boca del Cielo, la sexualidad se vuelve un arma vital para mujeres y varones. Ellos están conscientes que, aunque traten por todos los medios posibles de que sus esposas sean sólo madres, ellas no pueden renunciar fácilmente a hacer uso de sus cuerpos, deseos y poderes. Por ello consideran que es necesario tratar de controlar el cuerpo y las sexualidades de sus mujeres. Pero los hombres no sólo temen a los encantos, la manipulación, la infidelidad y el erotismo femeninos, sino también a la posibilidad de depender emocionalmente de una mujer que no sea la madre.

El deseo visto como iniciativa femenina es un arma temida por los varones - y las propias suegras - porque consideran que a ellos les es muy difícil controlar sus instintos sexuales y como no pueden prescindir de ellas, esto los expone a sus encantos, habilidades y corren el riesgo de hacerlos caer en sus redes, en la tentación. Así vista, la sexualidad femenina es un elemento subversivo que genera caos y desorden, por lo que es preciso mantenerla sobre vigilancia y control. De ahí la necesidad de separar conciencia y corazón, sentimiento y razón, sexualidad y

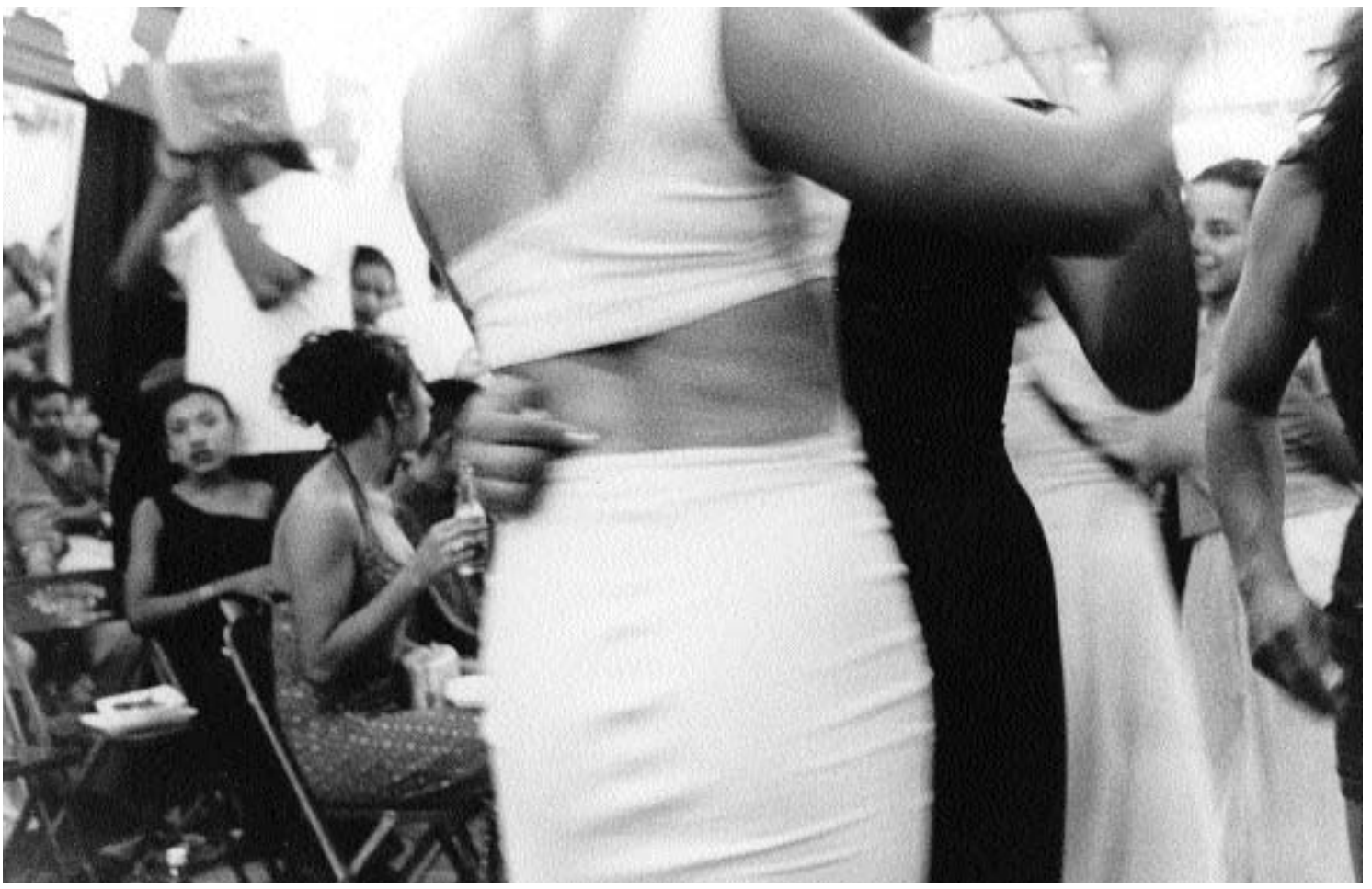

De espaldas al mundo, Jorge Acevedo 
afectividad. Por eso, con la esposa se tiene sexo para la reproducción y con las trabajadoras sexuales y las amantes por el placer mismo, a ella se le tiene en el altar, junto a la madre y la virgen. Con la cónyuge no se corre demasiado peligro siempre y cuando se mantenga la distancia y se conserve el dominio sobre ella; con las trabajadoras sexuales lo único que se pierde es un poco de dinero — pero se gana mucho prestigio—y momentáneamente el control, mismo que, una vez recuperado el aliento, vuelve a su lugar.

Temen lo que emana de la naturaleza femenina como la ternura, la cercanía, la pasión, el amor, la seducción. Quien se enamora, se entrega y pierde. ¿Qué es lo que se pierde? El dominio sobre sus sentidos, sentimientos, deseos, sobre sí mismo lo que significa ser débil, perder uno de los rasgos importantes de la virilidad. Debido al sistema sexo-género en que varones y mujeres estamos inmersos, las personalidades, actividades, sentimientos, subjetividades y roles genéricos están perfectamente delimitados: un hombre no puede actuar más que como el padrón hegemónico que de hombre-macho se le ha impuesto socialmente so pena de caer en la duda, el señalamiento, el desprestigio, la burla y/o la segregación. Los varones, constantemente están redefiniendo su identidad masculina en oposición a la femenina, el relacionamiento íntimo y cercano con el otro sexo les resulta peligroso porque es un terreno donde esa masculinidad impuesta puede ser fuertemente cuestionada.

En Boca del Cielo, los varones han sido educados y han crecido con la desconfianza hacia las mujeres, quienes son vistas no solamente como sus diferentes, sino como sus opuestos, sus contrarios. Sus madres — quién mejor que ellas para conocer los poderes femeninosles han inculcado ese temor porque, al reconocer a las otras mujeres (sus nueras) como sus rivales, los previenen en contra de su maldad, les abren los ojos para que no caigan, a través de la seducción, en sus redes y, los hagan débiles y poco hombres al grado que después no sirven más que para estar a mercé de sus caprichos y jugarretas. Por supuesto que los varones tienen negado el derecho de demostrar públicamente sus temores y debilidades, de ahí que magnifiquen "los contrapoderes" femeninos - mismos que no conocen a fondo--, pero que se encargan de divulgar entre ellos lo peligrosos que suelen ser para su sexo, aumentando así sus propios temores y coadyuvando a la institucionalización de la misoginia (Lacoste-Dujardin, 1993).

\section{RELACIONES HOMOERÓTICAS}

No obstante que sólo el 30 por ciento de la muestra estuvo de acuerdo en que la homosexualidad debe ser permitida, en general, los y las homosexuales del pueblo (sean chotos o lesbianas) no son excluidos de la sociedad, pertenecen a la gran familia boqueña, mujeres y hombres de todas las edades mantienen relaciones amistosas y cercanas con ellos-ellas. Ser homosexual no requiere de mayor explicación, simplemente nacieron así y punto: Son como un pescadito que salió con la colita chueca, me comentaron varias personas, e incluso algunas de ellas me dijeron: Todos nacemos con un don, ellos nacieron con el de la chotería. Forman parte de la naturaleza, de la misma manera que hay río y mar, hay homosexuales y heterosexuales, y los boqueños suelen no cuestionar lo que proviene de ese orden que consideran natural porque nada se puede hacer para modificarlo. De esta manera la homosexualidad es vivida por la sociedad local con bastante serenidad, permisividad (incluso con cierta participación); la orientación sexual no es motivo para cuestionar, sancionar o excluir.

Sin embargo, los comportamientos públicos de lesbianas y homosexuales masculinos son diferentes, así como su aceptación social. Nunca escuché a nadie expresarse mal de un homosexual (mujer o varón), nadie se refirió a ellos / ellas como enfermos, degenerados, anormales; tampoco observé nunca una actitud de rechazo o repudio; si acaso, entre las mujeres, exclamaciones de condolencia: Pobrecito desde chiquito era así, o de lástima: Es una lástima que fulano sea choto siendo tan guapo. Ellos / ellas no son juzgados por su preferencia sexual, sino como cualquier habitante del lugar por no respetar lo socialmente establecido, es decir, por ser borrachos, irresponsables, flojos, infieles, alocadas, fodongas, malas madres, etcétera.

Cuando los chotos están por llegar a algún lugar de reunión son anunciados por los gritos de los hombres, 
que los van chuleando o chiflando; entonces la gente se pone contenta pues saben que ellos traen alegría y diversión, esto es, reírse buena parte de la tarde o la noche, celebrando y compartiendo con ellos sus bromas, chistes picantes e historias (siempre referidos a lo sexual). A diferencia, la llegada de las lesbianas no es precedida por gritos ni algarabía popular. Aunque suelen ser también alegres, se comportan como cualquier mujer heterosexual, no le imprimen un sello especial al momento, no forman parte de la fiesta colectiva. Incluso, desde los primeros días de mi llegada al lugar, aparte de que rápidamente identifiqué a los homosexuales, la propia gente me los señaló y presentó como tales, como los chotos del pueblo; pero pasaron muchos meses para que algunas amigas de mucha confianza se atrevieran a decirme: $f u$ lana es lesbiana, al hacerlo no hubo connotación negativa, pero tampoco hubo más comentarios.

No podemos obviar decir que los homosexuales masculinos tienen mayor prestigio social que las femeninas, posiblemente esto se deba a que en una sociedad machista, sexista y con un rígida división genérica, las lessegunda categoría, con menores derechos y libertades que los varones, sobre todo en lo que se refiere al manejo de su sexualidad. Puede ser también que ellas representen un mayor cuestionamiento al orden genérico en la medida que renuncian a ocupar el papel que la sociedad les tiene asignado: la reproducción de la especie, al no ser madres no son mujeres, pero tampoco hombres porque no tienen pene y entonces los pobladores se preguntan: ¿qué son? Al mismo tiempo, ellas, transgreden la sexualidad genitalizada. Finalmente, los hombres aceptan al homosexual masculino por doble partida, en primera, porque consideran que entre sus esposas y los chotos no hay posibilidad de relacionamientos eróticos, y en segunda, porque con ellos sí pueden obtener placer; en cambio, en una sociedad como la nuestra en donde el falo es el símbolo del poder y el placer, ¿qué puede hacer una lesbiana sin pene? Suponen los pobladores que ni lograr identidad masculina, ni erotizar a otra mujer, ni ser codiciada por los varones. Algunas amigas del pueblo me preguntaban: ¿Cómo dos mujeres pueden obtener placer si no tienen con qué hacerlo?

Aunque conocí a varias mujeres lesbianas, algunas viviendo con su pareja, ninguna se asumió como tal, así que nunca me atreví a pedirles que me narraran sus vivencias; en algunas ocasiones, colateralmente, tocamos el tema y fueron los momentos en que aproveché para hacerles algunas preguntas de manera indirecta. Hablamos sobre entendidos, por lo que aquí describo son sólo apreciaciones muy generales. La gente sabe que son lesbianas porque, como dije anteriormente, en Boca del Cielo no existe la privacidad, todos saben todo acerca del vecino, del amigo, del pariente. Además, es evidente que forman parte del mismo grupo, no se casan ni tienen hijos, se visten y comportan de manera masculina, salen juntas a pasear y bailar, disimuladamente coquetean entre ellas y algunas viven, discretamente, con su pareja. Públicamente no confiesan sus preferencias eróticas, no andan por las calles del pueblo haciendo alarde de su homosexualidad, nadie les grita ni coquetea con ellas. Su comportamiento, su lenguaje y forma de vestir es discreto, cuidadoso. Sus familiares no comentan el hecho, la mayoría vive en casa con sus padres y, aunque algunos no están de acuerdo, las aceptan. Suelen ser muy trabajadoras, amables, alegres, bailadoras, cálidas, bebedoras, y, en confianza, albureras y picardientas. Gustan de relacionarse amorosa y sexualmente entre ellas mismas, pero su comportamiento respetuoso conlleva a que sean aceptadas socialmente y difícilmente marginadas o excluidas.

$\mathrm{Al}$ igual que los homosexuales varones, entre las parejas femeninas existe un división de roles: una es varón y otra mujer, no sólo en lo que a la repartición de tareas, actividades y responsabilidades se refiere, sino también en el ámbito sexual. El amor está ligado al ejercicio de su sexualidad, se enamoran, son fieles, no se prostituyen, no se casan, no tienen hijos. Algunas han tenido relaciones sexuales con varones, otras nunca, comentan que las relaciones entre mujeres son más satisfactorias, respetuosas, plenas, y suelen mantener relacionamientos estables y duraderos.

Los chotos, por el contrario, se asumen públicamente como homosexuales. Ninguno se negó a platicar conmigo y narrarme su historia de vida. Son mucho más abiertos, escandalosos y provocadores. Las mujeres heterosexuales comparten espacios con ellos, se convierten 


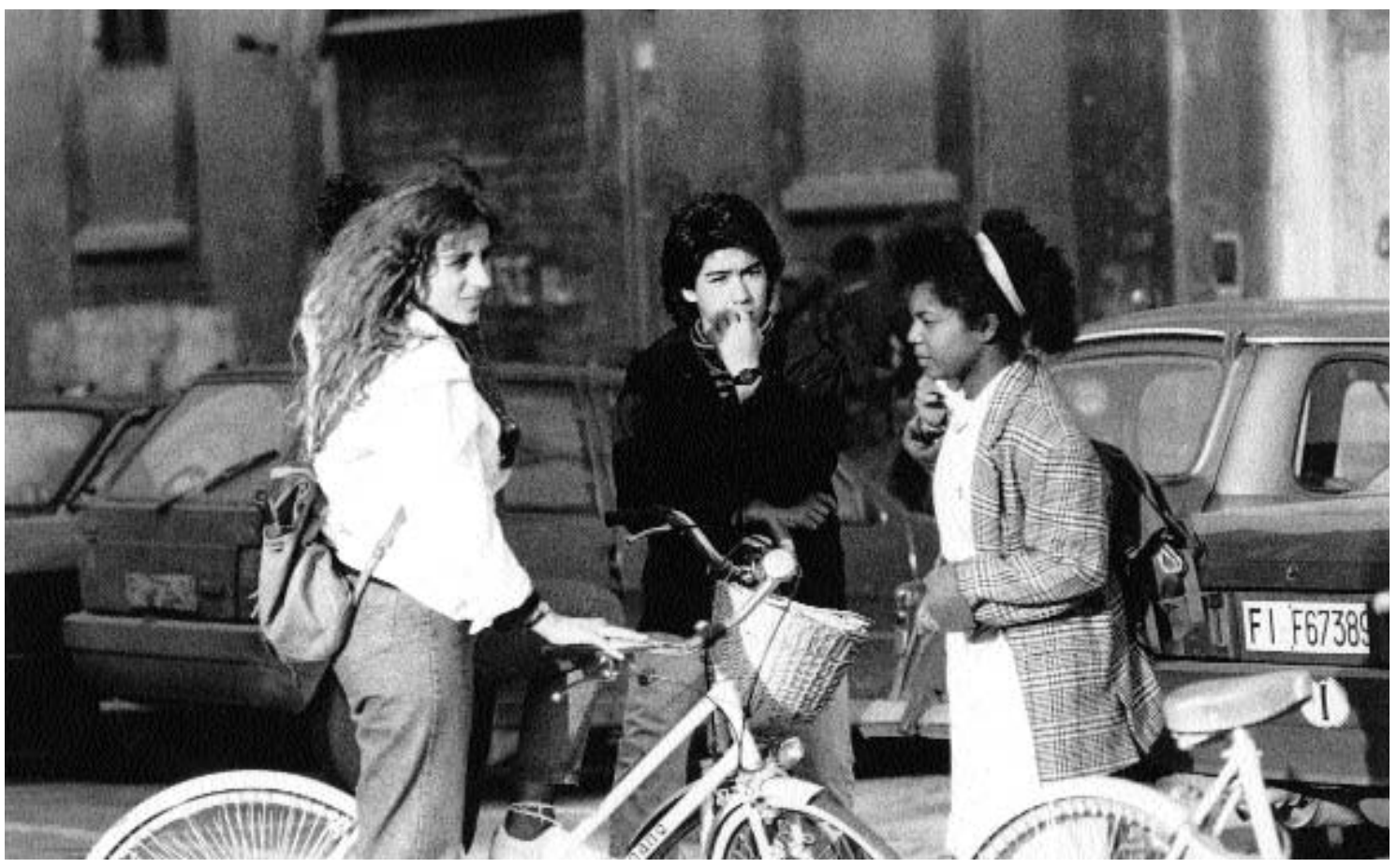

Razas, Jorge Acevedo

en sus confidentes y consejeras, gustan escuchar sus aventuras, bromas y chistes eróticos que celebran a gritos y carcajadas. Con las mujeres homosexuales llevan relaciones de complicidad. Los varones heterosexuales juegan todo el tiempo con ellos, los chulean, se empujan, se tocan los genitales y las nalgas, se mandan besos, algunos se relacionan sexualmente con ellos y otros se quedan con las ganas, conformándose con el cachondeo cotidiano.

Todos asumen que nacieron así y que por más que sus madres se preocuparon por darles tratamientos hormonales, incitarlos a relacionarse con mujeres, trataron de evitarles los juegos y comportamientos femeninos o en su defecto, ejercieron la violencia psicológica, física y verbal; ellos siempre gustaron de los juegos y las ropas de sus hermanas y, por supuesto, de los hombres heterosexuales. Al final, su familia acabó aceptándolos e incluso apoyándolos ante la imposibilidad de modificar su conducta, gustos y preferencias; viven con sus madres y hermanos, la mayoría no tiene padre y, en general, sus relaciones son cálidas y afectivas.
Se consideran hombres porque tienen pene, por el sexo, pero se asumen como homosexuales, como chotos (es un hombre que le gusta andar con otros hombres); gay es una palabra que no les gusta por ser extranjera. No se inyectan hormonas porque prefieren tener apariencia masculina, tampoco se operan porque su pene es importante en términos de su identidad genérica: un hombre es hombre porque tiene pene, consideran que sin él se sentirían fenómenos, no podrían tener relaciones sexuales, ni siquiera masturbarse. Argumentan que no pueden ser mujeres porque nacieron hombres, intentarlo sería una ofensa, en particular, para quien les dio la vida: su madre y, con ella no podemos competir, mucho menos opacarla. Reconocen que desearían haber nacido mujeres para poder tener un hijo propio, aunque al mismo tiempo descartan la posibilidad porque existen ciertas desventajas propias del género como menstruar, parir y cuidarse para poder sexuar sin tener hijos.

Sostienen que el pueblo los acepta porque ahí nacieron, los vieron crecer y desde que eran niños se dieron 


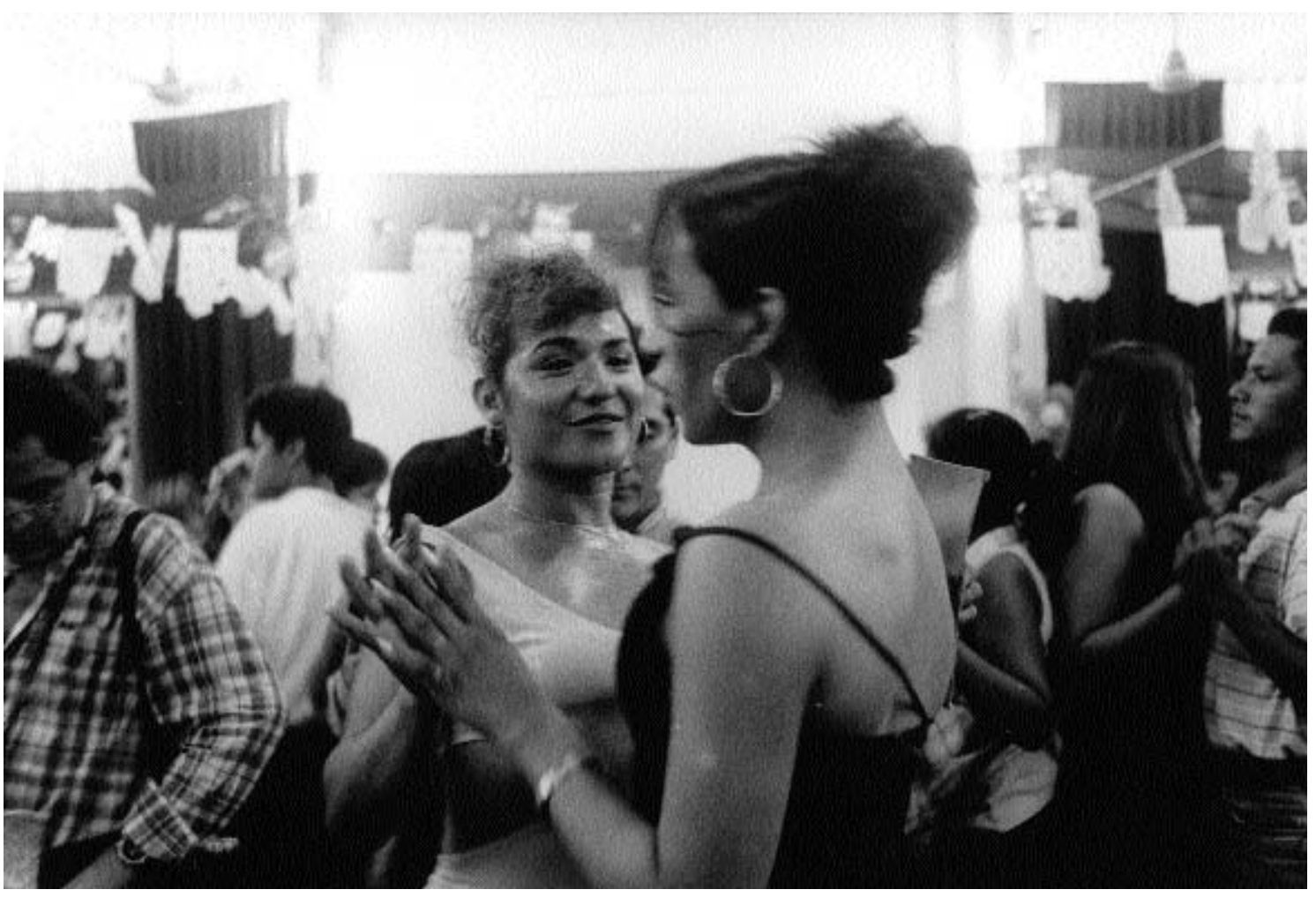

Sin título, Jorge Acevedo

cuenta que iban a ser homosexuales. Para ellos es importante asumirse como lo que son, sin engañar a nadie $y$ sin hipocresías, pues de ahí deviene la aceptación y el respeto colectivo. No obstante que no son rechazados o marginados, sienten que existe cierta discriminación social porque no pueden andar por las calles tomados de las manos, bailar abrazados o besarse en público y no falta quien los vea como raritos. Dicen que cuando eran chamacos había menos homosexuales y la gente les gritaba por las calles, pero como cada vez son más, poco a poco se han ido acostumbrando a ellos y ahora los ven como parte del cotidiano, ya no llaman la atención. En fin, reconocen que hay tolerancia, pero siempre y cuando respeten ciertas normas.

No rompen los códigos morales del lugar ni los de la propia masculinidad. Para ellos ésta es un mecanismo de aceptación, el eje principal de sus proyectos de identificación social. Son respetuosos de las normas genéricas establecidas y las reproducen al interior de sus parejas sean permanentes o eventuales, es decir, organizan su relación según el modelo heterosexual, en donde siempre uno hace el papel de hombre y otro el de mujer dentro de la casa, la cama y la vía pública. Reconocen y aceptan la rígida división sexista: lo femenino y lo masculino y todo lo que de ellos se desprende en términos de roles sociales y sexuales: la virginidad, fidelidad, maternidad, sumisión y dependencia femenina en contraposición a la autoridad, autonomía y libertades masculinas. Aunque son afeminados en su andar, movimientos de manos y gestos, no andan vestidos, peinados o pintados como mujeres, si acaso usan ropa justa y, algunos, sandalias consideradas de mujer.

No están organizados en ningún grupo gay pues sostienen que no es necesario porque ellos están integrados a la sociedad local y pueden convivir con su homosexualidad sin problemas; además, consideran que sería 
vergonzante y una falta de respeto para sus madres, su familia, andarse exhibiendo en lugares públicos exigiendo sus derechos. No todos están de acuerdo con la legalización del matrimonio homosexual, vía civil o religiosa, ni con la adopción, aunque a todos les gustaría tener hijos, pero siempre manifiestan su temor de que salieran homosexuales como ellos, y sufrieran en su infancia.

Son trabajadores y responsables; todos trabajan para mantenerse o ayudar a su familia en la economía del hogar. Unos son estilistas, algunos bailadores del son jarocho, otros empleados y uno que otro estudiante, y a veces, en sus ratos de ocio, hacen show travesti.

Gustan tener relaciones sexuales con varones heterosexuales, no con homosexuales, y en la cama prefieren ser penetrados. Sostienen que buena parte de sus galanes son bisexuales o bien también homosexuales, pues no conciben relaciones homoeróticas, es decir, que a un varón le guste otro varón, si esto sucede es porque son chotos reprimidos; consideran que a los verdaderos hombres les deben gustar solamente las mujeres. Prefieren a los casados porque creen que tienen mayor experiencia sexual, pero también saben que este tipo de relacionamientos conlleva mayores problemas por las esposas e hijos; tampoco gustan de relacionarse con niños ni adolescentes para evitar problemas con sus padres o la justicia. No obstante, reconocen que los muchachos se inician sexualmente con ellos ante la dificultad de ser aceptados, por su edad, en los prostíbulos, y por carecer de recursos para pagar los servicios. Narran que muchos de esos adolescentes se vuelven homosexuales pues les empiezan a gustar los chotos y continuamente los buscan; para otros es sólo una experiencia más, y la mayoría, cuando tienen acceso a una mujer, jamás regresan.

Los hombres heterosexuales que los buscan, denominados localmente mayates, sean solteros o casados, lo hacen para penetrarlos, pero casi todos, al final, piden ser penetrados. Estas relaciones se dan dentro del pueblo, con mucha discreción de ambas partes, nunca ninguno de ellos dio el nombre de ninguna de sus parejas; dicen que por eso también los varones-heterosexuales los respetan pues saben que ellos saben sus secretos. Ven mal que un hombre viva a expensas de un choto o viceversa, por la sencilla razón de que no consideran correcto que uno trabaje, gane dinero y el otro esté de flojo y mantenido; además, saben que tener trabajo y dinero les posibilita espacios de libertad y autonomía. No se prostituyen, ni cobran ni pagan, sostienen que, siendo jóvenes $y$ bonitas, no requieren que medie dinero, lo importante es el placer, pero en general aceptan invitaciones a comer, beber o presentes.

Aunque reconocen que se enamoran y sufren como cualquier hombre o mujer, para ellos el erotismo es imprescindible, no se acuestan sólo por amor, sino fundamentalmente por placer, el cual — sostienen— lo logran casi siempre en cualquier encuentro sexual, porque el simple hecho de ser penetrados les produce gozo. Sin embargo, gustan ser tratados sin violencia, con cariño, como personas y no como objetos. No son fieles aunque algunos conservan la misma pareja por muchos años a la cual le hacen creer que sí lo son, pero siempre encuentran la manera de engañarla; sostienen que si los descubrieran los abandonarían. Sus parejas, en el caso de los entrevistados, juegan el papel masculino, ellos sí pueden ser infieles, aunque no con mujeres, pero no les conceden el mismo derecho, por lo que ellos se lo toman procurando ser discretos. Comentan que sus maridos son celosos, que tienen que pedir permiso para salir con sus amigos, que si se tardan los regañan y muchas veces los golpean; por eso, la mayoría prefiere ser libre y no tener que estar dando cuentas a un cónyuge.

La reproducción de este modelo entre los homosexuales - masculinos o femeninos- posiblemente se debe a que no tienen referencia de otro diferente, no hay modelo alternativo; fueron educados dentro de familias y sociedades jerárquicas, machistas y sexistas. Tal vez también, en la medida que los reproducen, les permite ser mejor aceptados al no ser vistos como transgresores. Las relaciones homoeróticas tienden a cuestionar la dicotomía femenino-masculino, la idea de lo que significa ser hombre o mujer y el binomio heterosexual-homosexual, pero el modelo de valores y normas de comportamientos genérico no se modifica pues, una vez traslapadas las identidades genéricas dentro de las relaciones homoeróticas boqueñas, los papeles sexuales se reproducen: el que hace las veces de mujer se comporta como tal y viceversa. 
Ciertamente, la sociedad local prefiere el modelo tradicional heterosexual: hombre-mujer, pero también es cierto que tal aceptación de las relaciones homoeróticas nos habla de un trato más libre frente a la sexualidad, de una permisión mayor con el diferente, de cierta participación social frente al homoerotismo y, finalmente, de una opinión pública que no se rige por normas fijas y rígidas, sino flexibles, que tiende a adaptarse a las diversas circunstancias y a comprender la situación específica de los otros, esperando la misma tolerancia para su persona y actos. Ciertamente las diferencias entre los discursos normativos, la costumbre y las prácticas de este tipo de sociedades son evidentes; es más — y dicho sea de paso—- su estudio nos revela las dificultades y la complejidad de las propias relaciones sociales y los procesos de organización social en un país como México, que vive y transita permanentemente entre la tradición y la modernidad.

\section{REFLEXIONES FINALES}

En Boca del Cielo, mujeres y hombres comparten el discurso esencialista sobre las diferencias ontológicas de los sexos. Masculino es igual a proveedor, autoridad, espacio público, sexualidad instintiva y desbordante; en contraposición, mujer es madre, ámbito doméstico, sexualidad controlada y sumisión. Son diferentes debido a la marca inscrita en el cuerpo de ahí, que socialmente, se les atribuya estatus y papeles complementarios y opuestos. Pareciera ser que el objetivo de las relaciones de pareja es únicamente satisfacer las necesidades sexuales de los varones y la reproducción de la especie. Así, la posibilidad de una relación basada en proyectos propios y comunes, en relaciones amoroso-eróticas profundas se antoja imposible en estas latitudes, sin embargo, no podemos negar las diferencias, los rompimientos y los cambios que resultan del vivir de manera personal y colectiva. El predominio de la moral judeocristiana es evidente, sin embargo, existen espacios de resistencia, lucha y transgresión; es clara la coexistencia de valores, formas de pensamiento y prácticas "tradicionales" y "modernas" que se entrelazan en un proceso en donde se reproduce, se rompe y se transgrede al mismo tiempo.
Lo socialmente permitido para hombres y mujeres a través de las normas y valores se reproduce, algunas veces, cuando menos a nivel discursivo; parece éste una vía para identificarse con el grupo y lograr la interacción social. Pero al mismo tiempo existe un desfase entre la norma dicha y las que regulan sus prácticas sexuales, entre el modelo ideal y la realidad; en el discurso se quedan atrapados en el deber ser, en el cotidiano transgreden las preceptos establecidos (piensan de una manera y actúan de otra) y luego generan su propio discurso justificatorio. La frontera entre lo real y lo imaginario es bastante flexible cuando de ejercer la sexualidad se trata y se traslapa con bastante facilidad. Modifican los preceptos (legales o morales) que no están acordes con sus prácticas, pero los aceptan y defienden cuando coinciden con los ámbitos que comparten colectivamente en la comunidad.

Los datos muestran que las mujeres y los varones profesionistas son los que mantienen un discurso más "liberal" sobre la sexualidad, siendo pescadores, estudiantes (secundaria y bachillerato), amas de casa y trabajadoras sexuales el grupo más "tradicional”. Los adolescentes de cada uno de los sexos y solteros se destacan por ser más "conservadores" que sus padres; siendo los hombres — sin importar edad, escolaridad, profesión u oficio— los que manifiestan un discurso con mayor apertura sexual. En general, podemos sostener que a los varones les cuesta mayor trabajo cambiar sus comportamientos cotidianos que sus discursos; en contraposición, las mujeres tienen mayor resistencia para modificar sus representaciones que sus vivencias. Esto tiene varias explicaciones, en primer lugar hay que recordar que estamos hablando de discursos y que éstos se contradicen en la práctica; en segundo, en el caso de los / las profesionistas, esta aparente apertura puede tener distintas posibilidades explicativas, tal vez su respuesta corresponde al grado de escolaridad, a que pertenecen a una clase social diferente, o bien, que sea producto, solamente, de un discurso aprendido que tienen que asumir porque es el que se espera de ellos; en tercero, las mujeres son más cuidadosas al expresar sus necesidades, gustos y preferencias eróticas que los varones porque están más expuestas al señalamiento y a la crítica, además por razones que aluden a la educación genérica tienen mayores restricciones y menor 
permisibilidad familiar-social para ejercer su sexualidad de manera libre y, por supuesto, deben ser más cuidadosas si quieren gozar de prestigio social, conseguir o conservar marido, lograr un buen matrimonio y ser reconocidas como madres respetables; en tercer lugar, los jóvenes, al emitir su opinión, están reproduciendo un discurso heredado y transmitido por la familia, la sociedad, la religión y los medios de comunicación, en donde no han incorporado aún su experiencia de vida; a diferencia, sus progenitores, por experiencia, saben que la virginidad, la fidelidad, la sumisión o la violencia, de poco sirven para lograr un buen matrimonio, o que la masturbación y la homosexualidad a nadie afecta, pero tuvieron que pasar muchos años para que se dieran cuenta de ello; cuando esto sucede, sus hijos son adolescentes, ya les transmitieron sus valores y no hay posibilidad de dar marcha atrás. Así se inicia nuevamente el ciclo en la reproducción de la tradición. Finalmente, no se ha logrado construir un modelo valorativo alternativo que se pueda ofrecer a las nuevas generaciones.

No dejaré de insistir que, cuando hablamos de sexualidades en Boca del Cielo, no se puede hacer generalizaciones. Es preciso reconocer la diversidad, las permanencias y los cambios dentro del proceso de lucha continuo, que hombres y mujeres del lugar dan para resistir las normas culturales que tratan de impedir el despertar del cuerpo y sus pasiones.

Curiosamente, el erotismo, para cada uno de los sexos, pareciera estar permitido mientras se practique fuera de las relaciones matrimoniales: ellos lo ejercen con las trabajadoras sexuales, las queridas o en los encuentros homoeróticos, y ellas con sus novios o amantes. Es importante destacar que, de alguna manera, las prácticas sexuales de las boqueñas contradicen el mito de que la sexualidad femenina siempre está acotada a la reproducción, controlada, y gira en torno a las necesidades masculinas, también nos hablan de la posibilidad que tienen, como cualquier ser humano, para transgredir o modificar lo socialmente establecido, aun cuando de sexualidad se trate.

Uno de los grandes logros del feminismo ha sido mostrar que, a lo largo de la historia, los discursos y teorías médicos, religiosos y científicos han tenido como

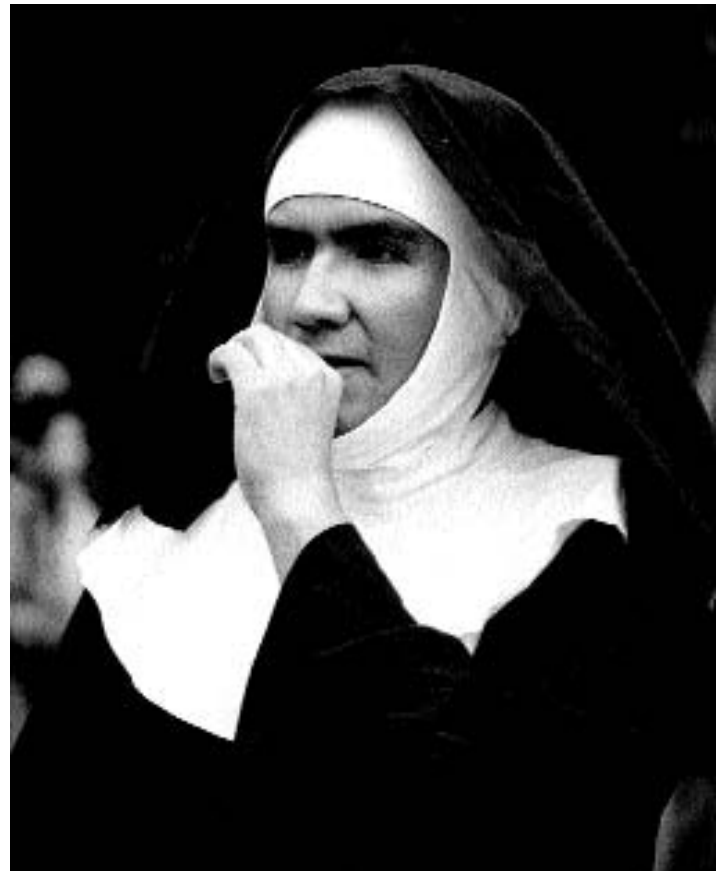

Sin título, Ricardo Ramírez Arriola

objetivo, por un lado, definir, categorizar y diferenciar a las mujeres en contraposición de los varones para demostrar la supuesta inferioridad, justificando la diferenciación sexual, la tutela masculina y su destino como reproductora de la especie, y por otro, tratar de controlar y normativizar el cuerpo, la sexualidad y reproducción femenina (Turner, 1989; op. cit., Foucault, 1993; op. cit., Weeks, 1998).

Ciertamente, los conceptos y esquemas sobre la sexualidad femenina - constantemente reformulados - son producto del poder que históricamente ha sido detentado por los varones, pero no hay que olvidar dos cosas: una, que si bien es cierto no se ha destruido el edificio de los privilegios masculinos ni se han modificado las concepciones en torno al destino biológico de las mujeres, las transformaciones logradas por éstas en el siglo XX nos demuestran que esto no es inmutable ni inevitable, y dos, si aceptamos que el poder y sus formas de dominación conllevan a la par luchas de resistencia, negociación y transgresión, debemos reconocer y revalorar que, en el campo sexual y reproductivo, las mujeres también han jugado 
un papel como sujetos activos y no sólo han sido víctimas inertes de la subordinación (Riquer, 1996; op. cit., Foucault, 1993; op. cit., Weeks, 1998; y op. cit., Núñez, 1994). En diversos momentos históricos los comportamientos de las mujeres nos demuestran que han renegociado, violado y transgredido los preceptos dominantes establecidos para reapropiarse de su cuerpo, reproducción, sexualidad, y han logrado definir sus deseos y necesidades.

Es decir, no obstante que existen normas y estereotipos acerca de la masculinidad y la feminidad que deben ser respetados para ser aceptados y/u obtener reconocimiento, no debemos perder de vista que la socialización no es únicamente un proceso de imposición de la normatividad ante el cual los seres humanos asumen de manera pasiva y homogénea. El conjunto de representaciones hegemónicas expresadas en leyes, discursos y prácticas son la fuente más importante que alimenta la construcción de nuestras subjetividades, pero afortunadamente, al mismo tiempo, los individuos tienen capacidad para elegir, aunque a veces dentro de marcos opresivos, frente a un amplio abanico de posibilidades, genérico dominante.

Desde esta perspectiva, vale la pena insistir en reconocer a las mujeres como parte de la diversidad humana, contradictoria y heterogénea, sin perder de vista aquellas pequeñas o grandes batallas cotidianas que han librado para transformar aquellos espacios que les resultan opresivos, en donde han opuesto resistencia y han manipulado las normas en favor de sus intereses, necesidades y propósitos. El poder también radica en la superación del estado involuntario de víctima, en la medida que seamos capaces de reconocer que somos corresponsables de un sistema sexista y jerárquico que insiste en equiparar la diferencia con la desigualdad, podremos transformar mínimamente nuestra cotidianeidad y podremos construir relaciones más equitativas y generosas, así como relacionamientos más íntimos en donde la pareja sea realmente pareja, y el amor y la sexualidad sean importantes, el primero asumido no como devoción eterna, sino como un medio de comunicación, elección y realización personal, y el segundo, como un encuentro íntimo de exploración y satisfacción del erotismo.

\section{Bibliografía}

Ariés, Philippe, 1987, "San Pablo y los pecados de la carne", en Ariés, Sexualidades occidentales, Paidós, México.

Caplan, P., 1987, "Introduction", en The Cultural Construction of Sexuality, Tavistoch Publications, Nueva York.

De Barbieri, Teresita, 1992, "Sobre la categoría de género. Una introducción teórica-metodológica”, en Revista Interamericana de Sociología, núm. 2, México.

Foucault, Michel, 1993, História da sexualidade, A vontade do saber, vol. 1, Ediçoes Graal, Río de Janeiro, Brasil.

Giddens, Anthony, 1991, A transformação das intimidades, Rosa Dos Tempos, São Paulo, Brasil.

Gordon, Linda, 1992, "Qué hay de nuevo en la historia de las mujeres", en Carmen Ramos (comp.), Género e historia, Antología Universitarias, Instituto Mora / UAM, México.

Lacoste-Dujardin, Camille, 1993, Las madres contra las mujeres. Patriarcado y maternidad en el mundo árabe, Cátedra / Universidad de Valencia / Instituto de la Mujer, Madrid, España.

Lamas, Marta, 1998, "Sexualidad y género: la voluntad del saber feminista", en Szasz y Lerner (comps.), Sexualidades en México. Algunas aproximaciones desde la perspectiva de las ciencias sociales, El Colegio de México, México.

Núñez, Guillermo, 1994, Sexo entre varones. Poder y resistencia en el campo sexual, El Colegio de Sonora / Coordinación de Humanidades / PUEG / Instituto de Investigaciones Sociales / Porrúa, México.

Ponce Jiménez, Patricia, 2000, Trabalho, poder e sexualidade. Histórias, valoraçoes e percepçoes femininas. Un estudo de caso na costa veracruzana, México, IFCH /UnICAMP, São Paulo, Brasil.

Rubín, Gayle, 1986, "El tráfico de mujeres. Notas para una economía política del género", en Nueva Antropología, núm. 30, México.

Riquer, Florinda, 1996, "La maternidad como fatalidad", en Lartigue y Ávila (comps.), Sexualidad y reproducción en México, vol. 1, Plaza y Valdés / UIA, México.

Scoot, Joan, 1996, "El género: una categoría útil para el análisis histórico", en Lamas (comp.), El género: la construcción social de la diferencia sexual, PUEG / UNAM, México.

Turner, Bryan, 1989, El cuerpo y la sociedad. Exploraciones en teoría social, FCE, México.

Vance, Carol et al., 1989, Explorando la sexualidad femenina, Revolución, Madrid.

Vance, Carol, 1991, "Anthropology Rediscovers Sexuality: Theoretical Comment", en Social Science and Medicine, vol. 33, núm. 8, Gran Bretaña.

Veyne, Paul, 1987, "El imperio romano", en Ariés y Duby, Historia de la vida privada, t. I, Taurus, Madrid.

Weeks, Jeffrey, 1998, Sexualidad, Paidós, PUEG, UNAM, México. 